\title{
A novel modelling approach to the identification of optimum sites for the placement of ocean thermal energy conversion (OTEC) power plant: application to the tropical island climate of Mauritius
}

\author{
Jay Rovisham Singh Doorga ${ }^{1}$. Oomarsing Gooroochurn ${ }^{1} \cdot$ Beenesh Anand Motah ${ }^{1} \cdot$ Vimal Ramchandur $^{1}$. \\ Shane Sunassee ${ }^{2}$
}

Received: 14 March 2018 / Accepted: 23 June 2018 / Published online: 3 July 2018

(c) The Author(s) 2018

\begin{abstract}
The geographical location of Mauritius near the warm tropical waters of the Indian Ocean coupled to the vast exclusive economic zone approximating 2.3 million square kilometers, encourage the promotion of ocean thermal energy conversion (OTEC) systems. Technological advancements have enabled offshore structures to pump the cold water lying at $1000 \mathrm{~m}$ depth in the seawater column to the surface, and through the temperature difference set up with the warm surface layer, drives a turbine and generates electricity. In this study, a model has been developed to compute the temperature difference between the deep $(1000 \mathrm{~m})$ and surface $(20 \mathrm{~m})$ seawater layers around Mauritius. An algorithm has been implemented to determine the net power generated from a proposed OTEC power plant, acquired through the processing of sea surface temperature satellite images, at a resolution of $1 \mathrm{~km}$. The spatial and temporal variations of the net power generated has been observed by splitting the annual data into four monsoonal time frames. Results show that the south-western region of Mauritius possesses high OTEC resources, with annual mean daily net power generation capacity of about $95 \mathrm{MW}$, representing about $20 \%$ of the peak power demand of the island. Moreover, the bathymetry of the southern region is propitious due to deep cold water availability at a proximity of less than $5 \mathrm{~km}$ from the coastline. The energy and exergy efficiencies of the OTEC system are found to be 1.9 and $22.8 \%$, respectively. A cost-benefit analysis indicates that profits of the order of 4.5 times the initial investment can be generated.
\end{abstract}

Keywords OTEC · Mauritius · GIS · Mathematical modelling $\cdot$ Satellite remote sensing $\cdot$ Energy economics

\section{Introduction}

The Small Island Developing State (SIDS) of Mauritius, situated near the subtropical latitude of the south-west Indian Ocean, benefits from a wealth of renewable energy resources. The favorable microclimate system associated to that region, characterized as both diverse and prevalent, encourages the development and exploitation of the available natural resources for energy self-sufficiency, based on

Jay Rovisham Singh Doorga

jdoorga@moi.intnet.mu

1 Physical Oceanography Unit, Mauritius Oceanography Institute, Avenue des Anchois, Morcellement de Chazal, Albion, Mauritius

2 Technical Unit, Mauritius Oceanography Institute, Avenue des Anchois, Morcellement de Chazal, Albion, Mauritius renewable energy generation. The abundance of sunshine received over the two seasons of the year has urged local authorities to integrate solar energy in the local energy mix. The year 2014 has seen the operationalization of the first solar farm in Mauritius, having installed power production capacity of 15.2 MW, with international expertise from Skytron Energy (Sarako Ltd) [1].

Besides the solar resource potential of the Island, the persistent south-east trade winds ensured by the position of the Intertropical Convergence Zone (ITCZ), incites the promotion of a number of wind and surface wave energy projects. A study performed by the Mauritius Oceanography Institute reveals the suitable wave climate of the eastern coasts of the island, with a mean power flux of $31.7 \mathrm{~kW} / \mathrm{m}$ recorded in the winter season [2]. The island relies on additional renewable energy resources, including hydroelectricity (3.3\%), bagasse $(16.3 \%)$ and landfill gas $(0.6 \%)$ to satisfy the electricity requirement of its expanding population dynamics 
[3]. Consequently, the diversification of its renewable energy resources has earned the island the position of being one of the most promising SIDS leading renewable energy development around the world.

The necessity of developing the renewable energy sector in SIDS stems from the impediment brought by the reliance on imported fossil fuels to satisfy the energy needs of the population. The fluctuations of fossil fuel prices on the international market bears economic repercussions on the financial structure felt by the small island economies. As highlighted in the Caribbean Community (CARICOM) implementation plan for climate change-resilient development, SIDS recognize the need to transcend towards low-carbon, climate-resilient economies [4]. The strategy involving the phasing out of fossil fuel imports, through the gradual penetration of renewable energy technologies, bears multiple benefits including energy security and environmental deliverance from the emission of harmful carbon dioxide gases in the atmosphere.

Considerable efforts have been made throughout the last decade to boost the renewable energy sector of the island. This is reflected by the fact that Mauritius ranked among the five developing countries to lead the investments per gross domestic product (GDP) on renewable energy (RE) technologies, with a total expenditure amounting to $0.75 \%$ of its GDP on environmental programmes back in 2012 [5]. With the allocation of a capital share in the recent 2017 national socio-economic budget to increase grid absorption capacity from intermittent renewable energy resources, the Government aided by local authorities, is seeking to attract the integration of efficient and newfangled forms of renewable energy facilities in the energy mix. The objective of which is to expand through diversification, the country's natural energetic resources [6].

Ocean waves, currents and offshore winds tend to provide power more continuously than land surface winds [7]. Furthermore, the electricity generated by photovoltaic systems suffers from the drawback of intermittence in electricity generation arising from the heterogeneity associated with the cloud systems. The relative attractiveness of ocean thermal energy conversion (OTEC) on the other hand lies in the fact that it can conceptually provide continuous base load power on the temporal scale [8]. OTEC is a method of converting the sensible heat of stored solar energy potential in the upper mixed layer of tropical and subtropical oceans into electricity by evaporating an appropriate working fluid in a Rankine cycle that operates between the warm upper surface layer and the cold deep bottom layer. The existing thermal stratification in the ocean column occurs due to the fact that warm water of the upper thermocline is inherently less dense and has, therefore, the tendency to rise above the denser cold deep water originating from polar regions and traveling towards the equator.
The conceptualization of the working principles behind the OTEC was first formulated in 1881 by the French physicist Jacques-Arsene D'Arsonval who proposed to use the warm surface water of tropical latitudes to vaporize pressurized ammonia through a heat exchanger to operate a turbine generator while the cold water pumped from deep ocean would then be used to re-condense the ammonia vapor in a closed, Rankine cycle. Additional modalities include the open-cycle OTEC whereby warm surface water introduced into a vacuum chamber is flash vaporized and drives a turbine generator, while the hybrid cycle OTEC combines the characteristics of both open and closed cycles systems. The OTEC principle, however, suffers from the drawback of low conversion efficiency resulting from the thermodynamic process. The upper threshold of this efficiency is dictated by the Carnot efficiency of $6.6 \%$, derived from the typical temperature difference of warm surface layer $\left(28^{\circ} \mathrm{C}\right)$ and cold bottom layer $\left(8^{\circ} \mathrm{C}\right)$ [9]. Consequently, large seawater flow rates of several cubic meters per second are needed to compensate for the low system efficiency.

Nonetheless, the quantity of seawater needed to operate an OTEC power plant is not an issue for SIDS, which despite of their limited land based natural resources, possess $20-25 \%$ of the world's most productive part of the ocean in their exclusive economic zone (EEZ) [10]. Hawaii became the first state in the United States to generate electricity from the closed-cycle onshore ocean thermal energy conversion process on August 2015, through the construction of a $105 \mathrm{~kW}$ plant connected to the grid in Kailua-Kona to provide electricity to 120 households [11]. A number of additional operational OTEC power plants currently exist around the globe, with the majority of them focused in the high ocean thermal resource potential of the Pacific, including the $30 \mathrm{~kW}$ Saga plant of Japan, $20 \mathrm{~kW}$ Gosung plant of Korea, and the $100 \mathrm{~kW}$ Kumejima plant of Japan, installed for the sake of research and development [12].

Sister Island, Reunion also falls in the group with an operational OTEC power plant of capacity $15 \mathrm{~kW}$ deployed in the Indian Ocean for research purposes [12]. Having recognized the potential of energy production from the thermal attribute of the ocean, a number of islands situated in the Pacific, Indian and North Atlantic Oceans are currently either in the construction phase or have planned for the construction of OTEC facilities in the near future. The Kwajalein Atoll of the Marshall Islands (20 MW), Tarawa Atoll of the Kiribati (1 MW), Maldives (2 MW), La Martinique (10 MW), New Providence of the Bahamas (10 MW) and St. Croix of the Virgin Islands (15 MW) are all in advanced phases pertaining to the construction of OTEC facilities [13].

The purpose of this paper is to provide an assessment of the resource potential for OTEC resource exploitation off the coasts of Mauritius. To the author's knowledge, the research methodology adopted involving a combination of 
geographic information system (GIS), remote sensing techniques along with mathematical modelling to identify the most promising regions around the island for OTEC development, is the first of its kind. The paper would be of interest at the national level and would provide the Government or any relevant organization with sufficient knowledge and incentives in making an informed decision with regard to major investments in OTEC.

The novelty of this paper is that it employs mathematical regression formulae based on the thermal stratification of the ocean water column, coupled to GIS modelling technique to predict the optimum site of OTEC plants. As compared to primitive equation general circulation models available, the proposed methodology is computationally less extensive and provides a relatively cheaper solution to the identification of optimum OTEC sites. To stress the novelty of the paper, we estimate the energy and exergy performances of the OTEC cycle for the proposed model. The organization of this paper is as follows: Sect. 2 discusses about the methods adopted; Sect. 3 presents the results; while Sect. 4 gives the conclusive remarks of the study.

\section{Methods and data}

\section{Study area}

The main island of Mauritius $\left(20^{\circ} 10^{\prime} \mathrm{S}, 57^{\circ} 30^{\prime} \mathrm{E}\right)$ forms part of the three group of islands including Reunion and Rodrigues to constitute the Mascarenes. The archipelago is situated in the south-west Indian Ocean (Fig. 1b) at a distance of $900 \mathrm{~km}$ to the east of Madagascar, off the eastern coasts of Africa. The island sits on the Mascarene Plateau which arches about $2000 \mathrm{~km}$ across the western Indian Ocean up to the Seychelles, with water depths reaching $100 \mathrm{~m}$ (Fig. 1a), highlighting the wide diversity of ecosystems supported by the shallow mid-oceanic plateau. The most interesting feature of the region are the aseismic formations including banks and plateaus, with seismically active mid-ocean ridges [14]. Both aseismic and seismic formations gave rise to a diversity of islands, including the granitic and coralline nature of the Seychelles and the volcanic nature of the Mascarene Islands.

The origin of the Mascarenes germs from the plateau, with the formation of Mauritius starting with the Breccia Series 10-7.8 million years (my) B.P. Three main domebuilding phases which comprise of a primary shield volcano, followed by the development of a caldera in the eastern part of the volcano and finally a new cycle of activity in the late Pliocene, gave rise to the geomorphology of Mauritius [15]. The morphological and paleoecological characteristics of fringing reefs as distinguished by the volcanic foundation, rate of vertical growth and overlap by reef-building

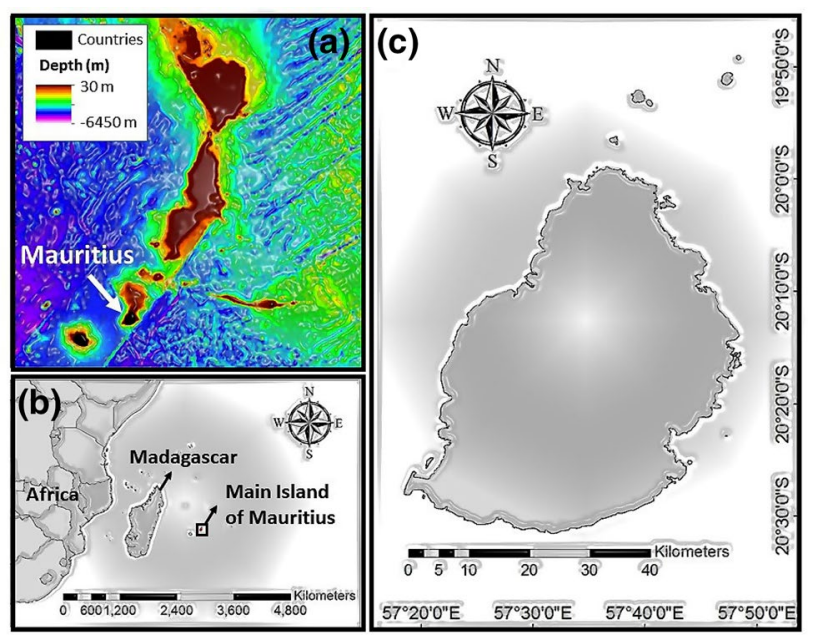

Fig. 1 a Bathymetric chart at one-minute resolution of the region around the coastal structure of Mauritius [data source: ETOPO1 made available from the National Oceanic and Atmospheric Administration (NOAA)]. b Geographical location of the tropical island of Mauritius, south-west of Indian Ocean basin. c Magnified view of the study area of Mauritius, part of the Mascarene group of Islands

organisms, is typical of the marine environment of Mascarene Islands. The coastline (Fig. 1c) measures about 200 $\mathrm{km}$ long and is composed of different shore types (categorized as sandy shores, rocky shores, muddy shores, mixed shores, calcareous limestone shores, cliffs and coastal wetlands), neighbouring a lagoon having an approximated area of $243 \mathrm{~km}^{2}$ and enclosed by the fringing reefs.

The island of Mauritius possesses a typical maritime climate with two distinct seasons: summer (November-April), characterised as warm and humid; winter (May-October), distinguished as cool and dry. Additionally, the position of the island near the Intertropical Convergence Zone (ITCZ) ensures persistent winds directed from the south-easterly direction throughout the year. The climate regime of monsoon and trade winds prevailing in the Indian Ocean is dictated by its geography and proximity to two large continental masses [14]. The occurrence of the monsoon regime is attributed to the transition season from summer to winter, resulting in the direction of average prevailing winds changing more than $90^{\circ}[16]$. This phenomenon dominates the northern region of the Indian Ocean while the patterns are present in the eastern and western extremes of the southern Indian Ocean. Within the Mascarene Plateau region, three climatic regimes are prevalent and encompasses the north-east monsoon from December to March, south-west monsoon from June to September and two inter-monsoonal periods which are dominant from April to May and from October to November.

The spatial and temporal movement of winds over the Indian Ocean is dictated by the latitudinal displacement of the ITCZ and varies strongly as a function of the season of 
the year. In the Northern Hemisphere winter, the air sitting over southern Asia is cooler and denser than the air sitting over the ocean. The resulting pressure gradient leads to a low-level north-easterly movement of air from the southern Asia towards south of equator, forming the north-east monsoon [17]. Due to the coriolis effect, the air movement is directed westwards and converges with the south-east trade winds at latitudes of $10^{\circ} \mathrm{S}-20^{\circ} \mathrm{S}$. This period corresponds to the rainy season in Mauritius, with the occurrence of frequent tropical cyclones and depressions which significantly influences the weather on the island. Over time, the air residing over Asia heats up, weakening the high pressure over Asia. Subsequently, by the month of June, the low pressure that is formed over Asia results in a sudden change in wind direction to south-westerly, giving rise to the south-west monsoon.

\section{Data inventory}

The relevant factors governing the identification of optimum sites for OTEC power plants include: bathymetry and sea surface temperature of the region of interest. A description of the available data and its influence in the current study is discussed below:

\section{Bathymetry}

Bathymetric chart of the water depth around Mauritius is an important criteria in determining the best locations for harnessing energy from the thermal content of the ocean. Due to the thermal stratification of the ocean column, the temperature at subsequent water level is a strong function of the water depth. The NOAA provided the detailed gridded bathymetry, the ETOPO1 dataset, at 1 arc minute resolution (Fig. 1a). The ETOPO1 data relies on the Sandwell and Smith [18] bathymetry data derived from sea-surface satellite altimetry measurements and ocean soundings with inclusion of supplementary detailed datasets.

\section{Sea surface temperature}

The sea surface temperature (SST) reflects the storage of thermal energy in the upper mixed layer of the oceans. The combination of SST and bathymetric data would help reveal the difference in temperature between the warm surface layer and cold bottom layer, thereby identifying zones around the island regarded as suitable for OTEC placement. The detailed variations on spatial scales of the temperature difference between the top-most- and bottom-most level of the water column is subsequently computed on the basis of SST and temperature variations with depth. Small differences in the temperature of the water column is expected to improve extractable power, and therefore, our analysis caters for minute changes on the three-dimensional level involving variations on both ocean surface and depth. It is revealed that for every $1^{\circ} \mathrm{C}$ increase in difference between the utilized warm and cold water resources, the extractable power increases by about $15 \%$ [19].

The SST data employed in the current study is a 3-day composite of sea surface temperature $\left({ }^{\circ} \mathrm{C}\right)$ at $1 \mathrm{~km}$ resolution acquired through satellite-based MODIS observations, provided in NetCDF format and processed by the Plymouth Marine Laboratory (PML). The temporal resolution of the data is daily spanning from 1st January 2017 to 31st December 2017, while the chart of SST for a 3-day composite in the vicinity of the Mascarene is illustrated in Fig. 2. During data pre-processing, pixels containing missing records arising from factors such as cloud cover and sun glint were substituted by NaN (Not-a-Number) to avoid errors in averaging computations over a certain time interval. The missing values corresponding to certain geographical coordinates for a typical day are represented as white zones in Fig. 2 for illustrative purpose.

\section{Temperature variations with depth}

The vertical temperature distribution in tropical and subtropical climates exhibits a profile of decreasing water temperature with increasing depth. Vertical profiles of temperature investigated at North Sulawesi and South Kalimantan of Indonesia vary to different extents according to the month of the year [20]. Similarly, the variation of temperature profile with depth of the seawater around Mauritius is expected to change according to the time of the year. To successfully model the thermocline trend as a function of the month of the year, we rely on the data provided by the AsiaPacific Data-Research Center through Argo profiles and the

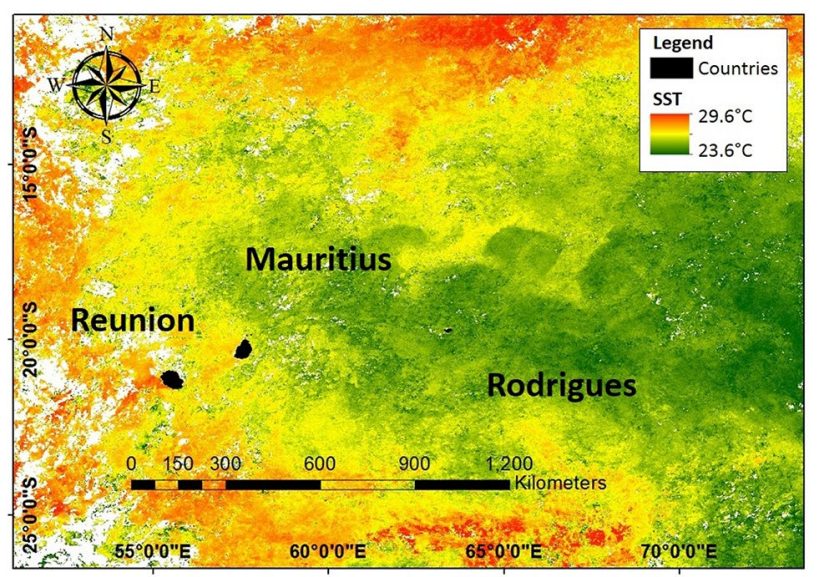

Fig. 2 Chart of sea surface temperature $\left({ }^{\circ} \mathrm{C}\right)$ acquired for a 3-day composite satellite imagery in the vicinity of the Mascarene at a resolution of $1 \mathrm{~km}$ 
satellite-based AVISO altimetry, provided in NetCDF format and interpolated in space using Variational Interpolation algorithm to minimize the misfit between the interpolated fields defined on a regular grid and the irregularly distributed data.

The data were collected and made freely available by the International Argo Program (http://www.argo.ucsd.edu, http://argo.jcommops.org). The Argo Program is part of the Global Ocean Observing System [21]. The Argo floats operate in a network of 2000-3000 floats, recording data such as temperature and salinity as a function of pressure. AVISO altimetry on the other hand was employed to calculate absolute dynamic depth. The temporal resolution of the data is monthly and spans from January 2010 to December 2012. The spatial resolution of the dataset is $1^{\circ}$ global with a vertical distribution of 27 levels from 0 to $2000 \mathrm{~m}$.

\section{Statistical Evaluation}

In the following subsection, a mathematical model will be derived to estimate the temperature variations as a function of depth. Consequently, to evaluate the performance of the model and compute its deviation from the actual recorded dataset, a set of statistical tool will be used. It comprises of the sum of squares error (SSE), coefficient of determination $\left(R^{2}\right)$ and root mean square error (RMSE) as defined below.

\section{Sum of squares error (SSE)}

The SSE is a measure of the variation of the dataset around a trend value or central number. The smaller the value, the more likely is the model estimates closer to the actual values. It is given by:

$$
\mathrm{SSE}=\sum_{i=1}^{n}\left(y_{i}-m_{i}\right)^{2}
$$

\section{Coefficient of determination $\left(R^{2}\right)$}

The coefficient of determination is a measure of the percentage variation of an estimated value. A value close to unity implies excellent fit between model estimates and actual data. It is given by:

$R^{2}=1-\frac{\sum_{i=1}^{n}\left(y_{i}-m_{i}\right)^{2}}{\sum_{i=1}^{n}\left(y_{i}-y_{\text {avg }}\right)^{2}}$

\section{Root mean square error (RMSE)}

The RMSE reflects the sample standard deviation of the differences between estimated and measured values. A value close to zero implies no spread about the regression line. It is given by:

$\mathrm{RMSE}=\sqrt{\frac{1}{n} \sum_{i=1}^{n}\left(y_{i}-m_{i}\right)^{2}}$

where $y_{i}$ and $m_{i}$ represent the $i$ th measured and estimated values, respectively. The average of recorded values is provided by $y_{\text {avg }}$ while $n$ gives the number of observations.

\section{OTEC plant model}

The computations involved in the current study is based on the OTEC plant model presented in this subsection. The formulated model estimates the net power production of a single OTEC plant given seawater temperature and depth of the cold water resource. The plant model stems from the $100 \mathrm{MW}$ net power/150 MW gross power closed cycle plant that Lockheed Martin/Makai Ocean Engineering designed as part of a contract with the U.S. Naval Facilities Engineering Command (NAVFAC) at Kahe Point situated in Hawaii [22]. The model represents a single-stage-, closed-cycle OTEC plant that operates using anhydrous ammonia as the working fluid as illustrated in Fig. 3.

The factors contributing to the net power production $\left(P_{\text {net }}\right)$ include: the gross power $\left(P_{\mathrm{G}}\right)$ which is established on the governing thermodynamic equations of the Rankine cycle, variable losses $\left(L_{\mathrm{var}}\right)$ associated with cold water pipe pumping, and fixed losses $\left(L_{\text {fixed }}\right)$ associated with all other pumping and transmission within the plant [23]. The net power of the OTEC plant is, therefore, given by:

$P_{\text {net }}(\mathrm{MW})=P_{\mathrm{G}}-L_{\text {fixed }}-L_{\mathrm{var}}$

The gross power production equation combines Carnot efficiency, Carnot to Rankine efficiency, and heat balance across the evaporator [9]. The equation formulated for gross power by Nihous [24] was amended to incorporate the propriety assumptions made by Lockheed Martin [23] $\left(P_{G}^{\mathrm{LM}}\right)$, which was then simplified to a linear Eq. [25] $\left(P_{\mathrm{G}}^{L}\right)$ as provided below:

$$
\begin{aligned}
P_{\mathrm{G}}^{\mathrm{LM}}(\mathrm{MW})= & \frac{106.22 \Delta T^{2}}{T_{\mathrm{S}}-0.25 \Delta T+273.15} \\
& \approx P_{\mathrm{G}}^{L}(\mathrm{MW})=13.89 \Delta T-149.71
\end{aligned}
$$

where $T_{\mathrm{S}}$ is the sea surface temperature $\left({ }^{\circ} \mathrm{C}\right)$ and $\Delta T$ is the temperature difference available for OTEC process $\left({ }^{\circ} \mathrm{C}\right)$.

The fixed losses, $L_{\text {fixed }}$, of the OTEC plant is provided by the specifications of the OTEC model, as presented in Table 1. Through these specifications, the losses arising from cold water intake, condenser and distribution pumping, 
Table 1 Specifications of the OTEC plant model with a rating of $100 \mathrm{MW}$ net/150 MW gross power

\begin{tabular}{ll}
\hline Plant model specifications & Numerical value \\
\hline Warm water mass flow rate & $460,000 \mathrm{~kg} / \mathrm{s}$ \\
Cold water mass flow rate $(\dot{m})$ & $366,000 \mathrm{~kg} / \mathrm{s}$ \\
Ammonia mass flow rate & $4060 \mathrm{~kg} / \mathrm{s}$ \\
Turbine expander efficiency & $86 \%$ \\
Ammonia pump efficiency & $75 \%$ \\
Seawater pump efficiency $(\eta)$ & $80 \%$ \\
Generator efficiency & $97.5 \%$ \\
Evaporator UA $\left(\mathrm{UA}_{\text {evp }}\right)$ & $1410 \mathrm{MW} /{ }^{\circ} \mathrm{C}$ \\
Condenser UA $\left(\mathrm{UA}_{\text {con }}\right)$ & $1350 \mathrm{MW} /{ }^{\circ} \mathrm{C}$ \\
Head loss due to friction $\left(h_{\mathrm{f}}\right)$ & $0.0008356 \mathrm{z}$ \\
Gravitational constant $(g)$ & $9.81 \mathrm{~m} / \mathrm{s}^{2}$ \\
Friction factor $(f)$ & 0.007933 \\
Pipe diameter $(D)$ & $10 \mathrm{~m}$ \\
Pipe intake area $(A)$ & $78.5 \mathrm{~m}{ }^{2}$ \\
Head loss water density $\left(\rho_{f}\right)$ & $1025 \mathrm{~kg} / \mathrm{m}^{3}$ \\
Water density $(\rho)$ & $\left(-0.00599 T^{2}\right.$ \\
& $+0.031 T+1025)$ \\
& $\mathrm{kg} / \mathrm{m}^{3}$ \\
\hline
\end{tabular}

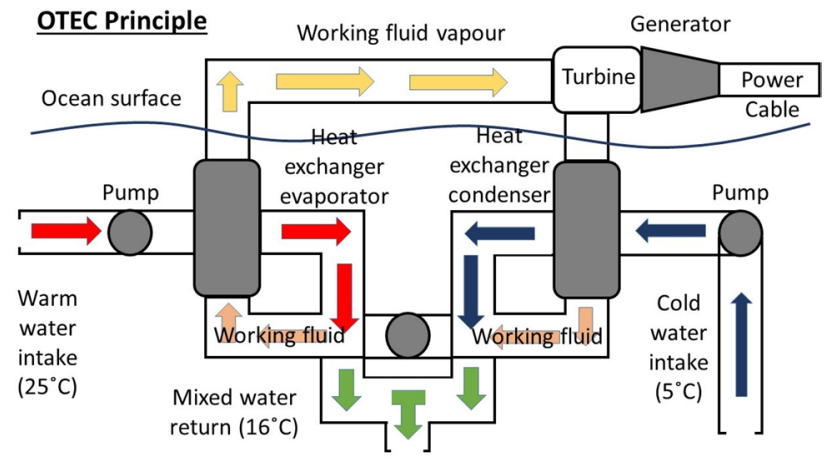

Fig. 3 Schematic diagram of the OTEC plant model for Kahe Point, Hawaii

evaporator and distributing pumping, and ammonia pumping were computed. A detailed description of these losses is provided in a paper presented by Ascari et al. [25], which results in a total fixed loss given by:

$L_{\text {fixed }}(\mathrm{MW})=42.7$

The variable losses, $L_{\mathrm{var}}$, of the OTEC plant is the sum of pipe friction loss, $L_{\mathrm{pf}}$, and static head loss, $L_{\mathrm{sh}}$ :

$L_{\mathrm{var}}(\mathrm{MW})=L_{\mathrm{pf}}+L_{\mathrm{sh}}$

Where pipe friction loss is a function of the water velocity, smoothness and diameter of the pipe. Through substitution of the appropriate roughness coefficient and Reynold's number, the pipe friction loss is given by:

$L_{\mathrm{pf}}(\mathrm{MW})=\frac{h_{\mathrm{f}} \dot{m} g}{\eta}=\frac{f\left(\frac{\dot{m}}{\rho_{f} A}\right)^{2} \dot{m} g}{2 D g \eta} z=0.0038 z$

where $z$ is the vertical water-column coordinate $(m)$.

The static head loss on the other hand is acquired through integration along the full length, of the density difference between the cold water inside the pipe and the warmer water on the outside of the pipe, as a function of depth. Due to unavailability of density against depth profiles in the region of investigation, an approximation is made using a simplified formula for static head accompanied by a bias correction formulated through comparison of the results stemming from the simplified method with results from the integration approach along a representative pycnocline [23]. Therefore, the static head loss is a product of pump power loss, static head bias correction, and simplified static head loss, as shown below:

$L_{\mathrm{sh}}(\mathrm{MW})=\left(L_{\mathrm{pp}} \times L_{\mathrm{ssh}} \times C_{\text {shb }}\right)$

where $L_{\mathrm{pp}}$ is the pump power loss, $L_{\mathrm{ssh}}$ is the simplified static head loss, and $C_{\text {shb }}$ is the static head bias correction. These are computed as follows:

$$
\begin{aligned}
L_{\mathrm{pp}}(\mathrm{MW}) & =\frac{\dot{m} g z}{\eta}=4.488 z \\
L_{\mathrm{ssh}}(\mathrm{MW}) & =\frac{\rho_{D}-\rho_{S}}{\rho_{D}} z \\
& =\left(\frac{-0.00599 T_{\mathrm{S}}^{2}+0.031 T_{\mathrm{S}}+1025}{-0.00599\left(T_{\mathrm{S}}-\Delta T\right)^{2}+0.031\left(T_{\mathrm{S}}-\Delta T\right)+1025}-1\right)
\end{aligned}
$$

$C_{\text {shb }}=5.234 \times 10^{-10} z^{3}-1.378 \times 10^{-6} z^{2}+1.313 \times 10^{-3} z-0.6541$

\section{OTEC cycle component}

The schematic diagram of the OTEC cycle under investigation is presented in Fig. 4a. The governing principles are as follows: (1) The working fluid is transformed to high pressure vapor due to heat being transferred from the warm surface seawater into the evaporator; (2) The vapor journeys through the mist separator and into the turbine. The pressure change between the turbine inlet and outlet drives the latter and generates electricity; (3) Depressurization of 
Fig. 4 a Schematic diagram of the OTEC cycle under investigation. b P-H representation of the OTEC cycle under investigation. Adapted from Yoon et al. [32]

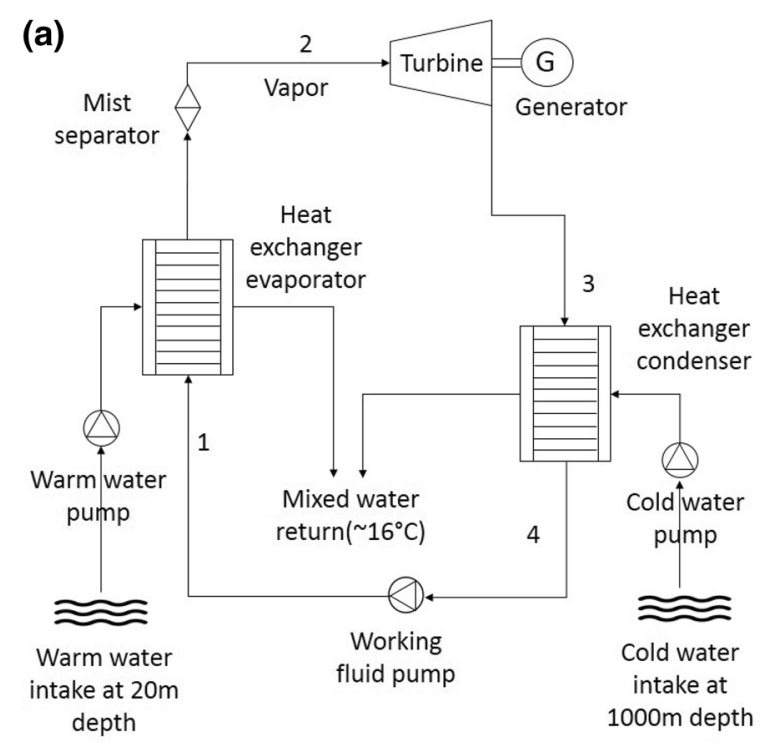

(b)

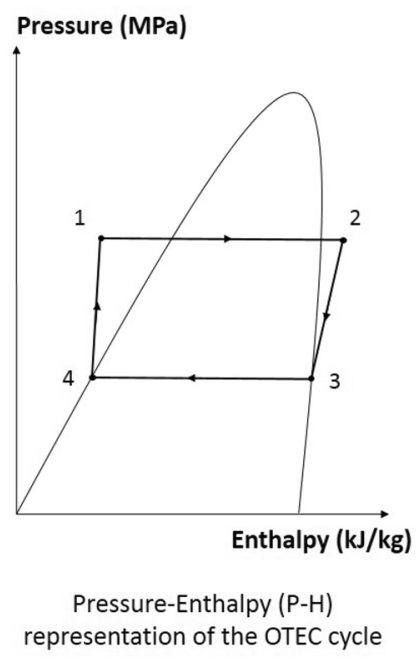

the working fluid to the condensation pressure takes place and the vapor-state working fluid is condensed due to heat exchange with the cold deep seawater; (4) The working fluid pump circulates the liquid-state working fluid to complete the cycle.

The pressure-enthalpy (P-H) diagram of the OTEC cycle is presented in Fig. 4b. As described by Yoon et al. [32], the transformation from 1 to 2 represents the transfer of heat between the working fluid and the warm surface seawater [32]. Transformation from states 2 to 3 represents departure from isentropic expansion process of the working fluid in the turbine. States 3-4 depicts the transformation due to condensation process in the heat exchanger condenser. Transformation from states 3 to 4 represents the pressurization process of the condensed working fluid to the evaporation pressure by the working fluid pump.

The energy efficiency $\left(\eta_{\text {otec }}\right)$ of the OTEC system is defined as the ratio of the net power output to the input energy at evaporator, and can be expressed as [26]:

$\eta_{\text {otec }}=\frac{P_{\text {net }}}{\dot{Q}_{\text {evp }}}$

where $\dot{Q}_{\text {evp }}$ is the heat transfer rate of the evaporator and is evaluated as:

$\dot{Q}_{\text {evp }}=\mathrm{UA}_{\text {evp }} \Delta T$

where $\mathrm{UA}_{\text {evp }}$ is obtained from Table $1 ; \Delta T$ is the mean temperature difference of the evaporator and amounts to a constant value of $3.56{ }^{\circ} \mathrm{C}$ in accordance to the OTEC model design used in the current study [25].
The exergy efficiency $(\Psi)$ of the OTEC system is defined as the relative measure of the performance of the OTEC cycle as compared to the reversible Carnot cycle operating under same conditions, and is given by [27]:

$\Psi=\frac{\eta_{\text {otec }}}{\eta_{\text {carnot }}}$

where $\eta_{\text {carnot }}$ is the Carnot efficiency and is given by:

$\eta_{\text {carnot }}=1-\frac{T_{\mathrm{cw}}}{T_{\mathrm{ww}}}$

where $T_{\mathrm{ww}}$ is the warm water intake temperature; and $T_{\mathrm{cw}}$ is the cold water intake temperature.

\section{Modelling stratagem}

Commercial-scale OTEC plant needs to have a cold water pipe (CWP) length of about $1000 \mathrm{~m}$ for successful operation [28]. Shallow water temperature is generally defined at the assumed depth of the shallow water intake pipe of $20 \mathrm{~m}$, while deep water is assumed to be derived from the deepest point in the vertical column to a maximum depth of $1000 \mathrm{~m}$ [9]. Consequently, the OTEC model designed to be constructed in the vicinity of the island is conditioned to operate between the warm water temperature at $20 \mathrm{~m}$ depth and cold water temperature at $1000 \mathrm{~m}$ depth. The thermocline models developed for the four temporal windows are used to calculate the seawater temperatures at 20 and $1000 \mathrm{~m}$ depth. Potential temperature decreases downward through the thermocline into a much more 
uniform, colder temperatures at depth [29]. Consequently, the performance of the OTEC plant on spatial scales is dictated to a greater extent by the temperature of the surface layer than the temperatures lying deep down the seawater column.

The average temperature on spatial scales at depth of $1000 \mathrm{~m}$ near the vicinity of Mauritius on a rectangular frame of dimensions $200 \mathrm{~km} \times 200 \mathrm{~km}$ is derived. The rectangular frame is first generated in ArcGIS environment and then the mean value is computed using zonal statistics function available under the Spatial Analyst Tools. The temperature difference between the variable surface temperature on spatial scales at depth of $20 \mathrm{~m}$ and the constant mean bottom temperature at depth of $1000 \mathrm{~m}$ is computed. The temperature difference obtained is then substituted in Eq. (17) below, which is in fact derived from Eqs. (4)-(12). The equation is subsequently used to calculate the net power potential of OTEC resources around Mauritius. The flowchart methodology summarizing the adopted strategy in this paper is presented in Fig. 5.

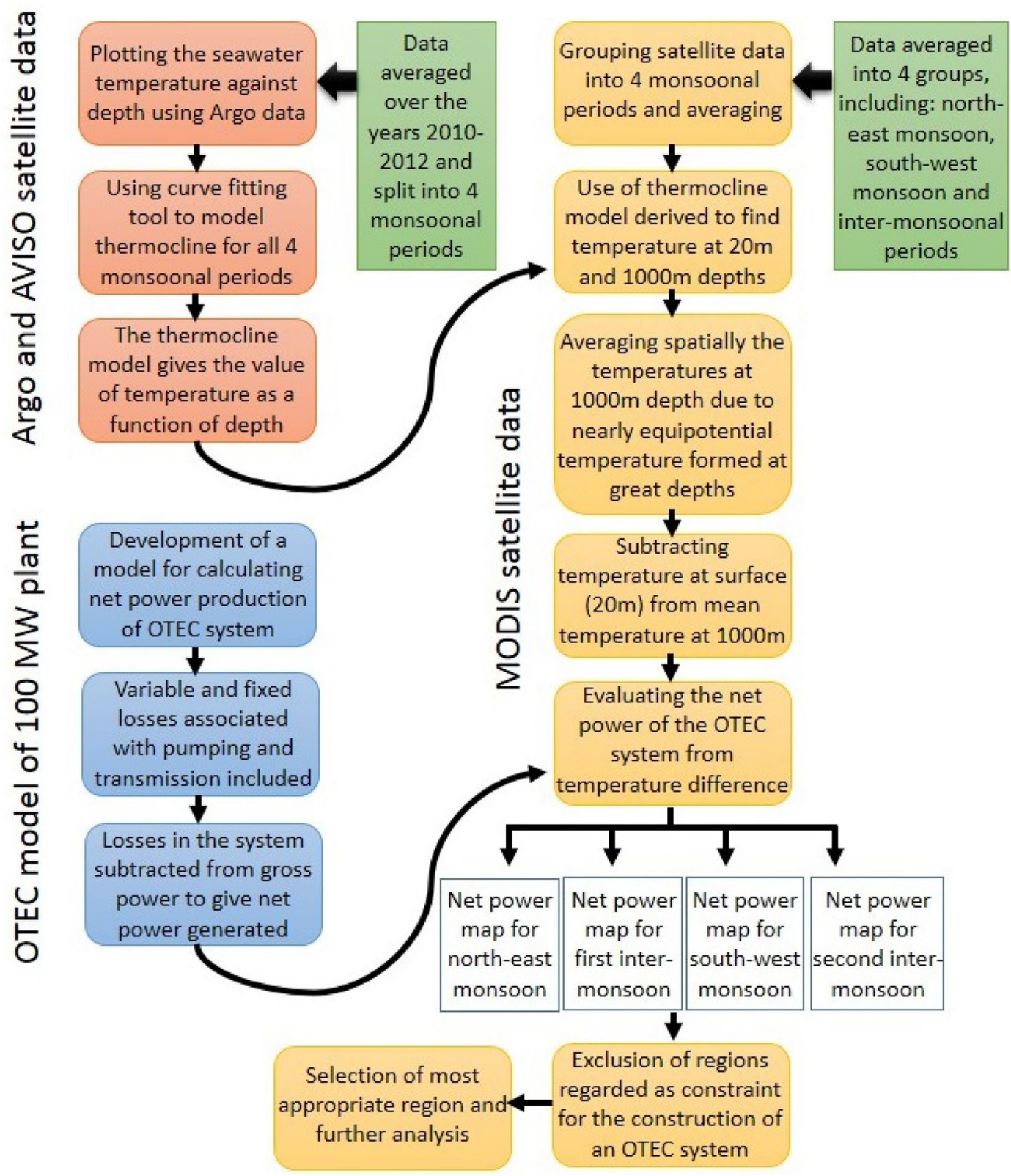

Fig. 5 Methodological flowchart illustrating the main procedures undertaken to identify the high energy potential sites around Mauritius for the placement of an OTEC power plant 


$$
\begin{aligned}
P_{\text {net }}(\mathrm{MW})= & 13.89 \Delta T-149.71-42.7-0.0038 z- \\
& {\left[4.488 z \times\left(\frac{-0.00599 T_{\mathrm{S}}^{2}+0.031 T_{\mathrm{S}}+1025}{-0.00599\left(T_{\mathrm{S}}-\Delta T\right)^{2}+0.031\left(T_{\mathrm{S}}-\Delta T\right)+1025}-1\right)\right.} \\
& \left.\times\left(5.234 \times 10^{-10} z^{3}-1.378 \times 10^{-6} z^{2}+1.313 \times 10^{-3} z-0.6541\right)\right]
\end{aligned}
$$

\section{Results and discussions}

\section{Thermocline model development}

The first step in the thermocline model development is the selection of an appropriate seawater site near the coasts of Mauritius that is deep enough to observe the variations of temperature profile with depth. Consequently, the seawater column $A\left(20.5^{\circ} \mathrm{S}, 58.5^{\circ} \mathrm{E}\right)$ was selected for investigation as depicted in Fig. 6a. One of the criteria for selection was that the site should be at some distance from the elevated Mascarene Plateau. Once the point of interest on the geographic coordinate system has been identified, the next phase involves the development of a script on the MATLAB R2015a development environment to extract the temperature at respective depths using an Intel(R) Core(TM) i5-6500 operating at $3.20 \mathrm{GHz}$ with $8 \mathrm{~GB}$ central processing unit on a Windows 7 platform.

The monthly values for the temperatures at all 27 levels of water column $A$ from surface layer to $2000 \mathrm{~m}$ depth were extracted. Averaging of extracted monthly datasets was carried out for the years 2010-2012 to account for the effect of climatic variability on the temporal scale. Some additional coordinates around the island were selected and the data extracted were cross-validated with dataset of coordinate $A$. Due to small differences observed in the thermoclines of datapoints around the island, we choose the dataset of point $A$ as a representative of the general trend of the thermocline for the locality of the island. The monthly datasets were then grouped into four main temporal windows which include the north-east monsoon, first inter-monsoon, south-west monsoon and second intermonsoon. The grouping was performed by averaging the temperature values corresponding to the same depth for respective temporal windows. A plot of the temperature profile with depth for the four monsoonal periods is illustrated in Fig. 6b.

The model development was performed on MATLAB using the curve fitting tool to obtain the best fit between the extracted measured datasets and the modeled ones. The process was repeated on all four monsoonal periods. A polynomial function was selected due to the reasonable flexibility in fitting curve for data that is not too complicated, in addition to relatively simple fitting process [30]. Furthermore, from the polynomial fit, the intercept of the curve on the y-axis can be obtained through the constant function. The constant function for the case of the thermocline is simply the sea surface temperature. Consequently, the polynomial function enables a relationship to be established between the seawater temperature and depth while involving a constant function in the form of the sea surface temperature. The thermocline model would be able to estimate the temperature of seawater at a certain depth in the water column, given the sea surface temperature and depth. Nonetheless, the theoretical model is based on the assumption of uniform potential temperature of seawater which ensures good thermal stratification irrespective of the depth of the water column.

For the north-east monsoon, the polynomial fit describing temperature of seawater as a function of depth and sea surface temperature is given by:

$T=7.144 \times 10^{-09} d^{3}+3.145 \times 10^{-05} d^{2}+0.04748 d+T_{\mathrm{S}}^{\mathrm{NE}}$

where $T$ is temperature in ${ }^{\circ} \mathrm{C}, d$ is the depth in $\mathrm{m}$ and $T_{\mathrm{S}}^{\mathrm{NE}}$ is the sea surface temperature corresponding to north-east monsoon, with the equation applicable for $0 \geq d \geq-2000$.

For the first inter-monsoon, the polynomial function is given by:

$T=7.533 \times 10^{-09} d^{3}+3.255 \times 10^{-05} d^{2}+0.04809 d+T_{\mathrm{S}}^{\mathrm{FI}}$

where $T_{\mathrm{S}}^{\mathrm{FI}}$ is the sea surface temperature corresponding to first inter-monsoon period, with the equation applicable for $0 \geq d \geq-2000$.

Table 2 Mathematical models of best fit polynomial trends corresponding to the four temporal windows under investigation

\begin{tabular}{lllll}
\hline Temporal window & Polynomial fit & SSE & $R^{2}$ & RMSE \\
\hline North-east monsoon & Eq. (4) & 3.322 & 0.9987 & 0.3801 \\
First inter-monsoon & Eq. (5) & 7.722 & 0.9969 & 0.5794 \\
South-west monsoon & Eq. (6) & 13.83 & 0.9933 & 0.7754 \\
Second inter-monsoon & Eq. (7) & 9.581 & 0.9954 & 0.6454 \\
\hline
\end{tabular}




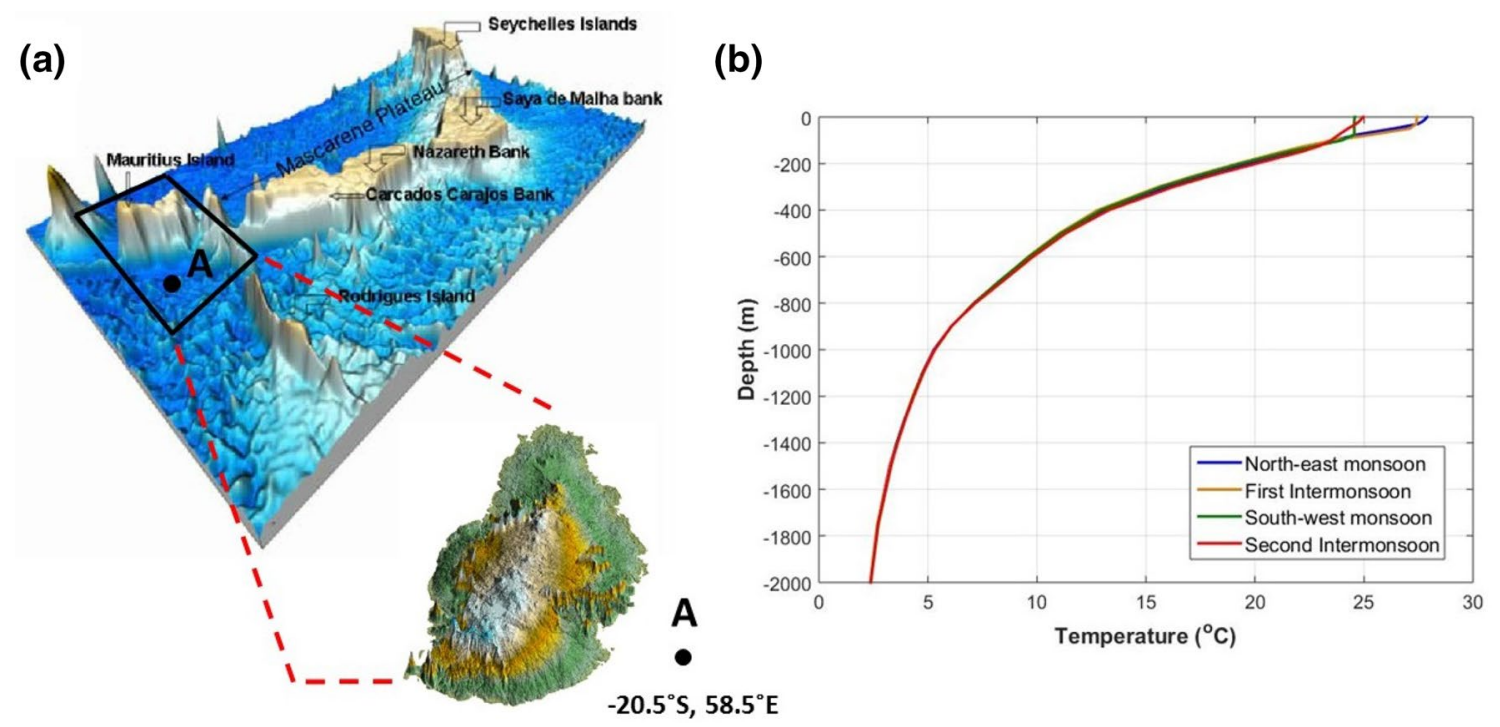

Fig. 6 a Geographical position of the point of investigation (A) on the sea floor topography acquired from altimetry and echo sounding, (data source: ETOPO1 and National Geophysical Data Centre [31])

Table 3 Analysis of variance (ANOVA) of thermoclines belonging to different monsoonal time frames

\begin{tabular}{llllll}
\hline & $\begin{array}{l}\text { Sum of } \\
\text { squares }\end{array}$ & Df & Mean square & $F$ & $P$ value \\
\hline $\begin{array}{l}\text { Between } \\
\text { groups }\end{array}$ & 9.52 & 3 & 3.1727 & 0.04 & 0.9907 \\
Within groups & 9115.15 & 104 & 87.6457 & & \\
Total & 9124.67 & 107 & & & \\
\hline
\end{tabular}

For the south-west monsoon, the polynomial function is given by:

$T=4.355 \times 10^{-09} d^{3}+2.192 \times 10^{-05} d^{2}+0.03814 d+T_{\mathrm{S}}^{\mathrm{SW}}$

where $T_{\mathrm{S}}^{\mathrm{SW}}$ is the sea surface temperature corresponding to south-west monsoon, with the equation applicable for $0 \geq d \geq-2000$.

For the second inter-monsoon, the polynomial function is given by:

$T=3.898 \times 10^{-09} d^{3}+2.053 \times 10^{-05} d^{2}+0.03722 d+T_{\mathrm{S}}^{\mathrm{SI}}$

where $T_{\mathrm{S}}^{\mathrm{SI}}$ is the sea surface temperature corresponding to second inter-monsoon period, with the equation applicable for $0 \geq d \geq-2000$.

The goodness of fit corresponding to the polynomial functions on all four temporal windows is included in Table 2. From results pertaining to the sum of squares errors, coefficient of determinations and root mean square b Temperature variations with depth for the four temporal windows: North-east monsoon, south-west monsoon and the two inter-monsoonal periods at point $\mathrm{A}$

errors, it can be inferred that the proposed models fit the empirical datasets well. This is supported by the low sum of squares and root mean square errors, in addition to the coefficient of determinations close to unity.

\section{Statistical differences among monsoonal thermoclines}

In view of determining whether significant differences exist among the thermoclines belonging to the four monsoonal periods of interest and derived from point $A$, an analysis of variance (ANOVA) test is performed. Table 3 reveals the results obtained from the analysis conducted. Initially, the two hypotheses are:

- $H_{0}$ : No significant difference exists among the thermoclines belonging to different monsoonal periods.

- $H_{1}$ : Significant differences exist among the thermoclines belonging to different monsoonal periods.

The ANOVA test suggests that no significant differences $(F=0.04, P-$ value $=0.9907)$ exist among the thermoclines belonging to the four monsoonal periods. The null hypothesis is therefore accepted. We probe into the statistical interpretations of the datasets to analyse the variations through a boxplot corresponding to the respective monsoonal time frames as illustrated in Fig. 7.

From the boxplot, it can be noticed that the minima and lower quartiles, belonging to the four monsoonal periods and corresponding to the seawater temperatures at great depths, 
Fig. 7 Boxplot representing the distributions of seawater temperature for water depths in the range $0-2000 \mathrm{~m}$ and grouped according to the four monsoonal time frames

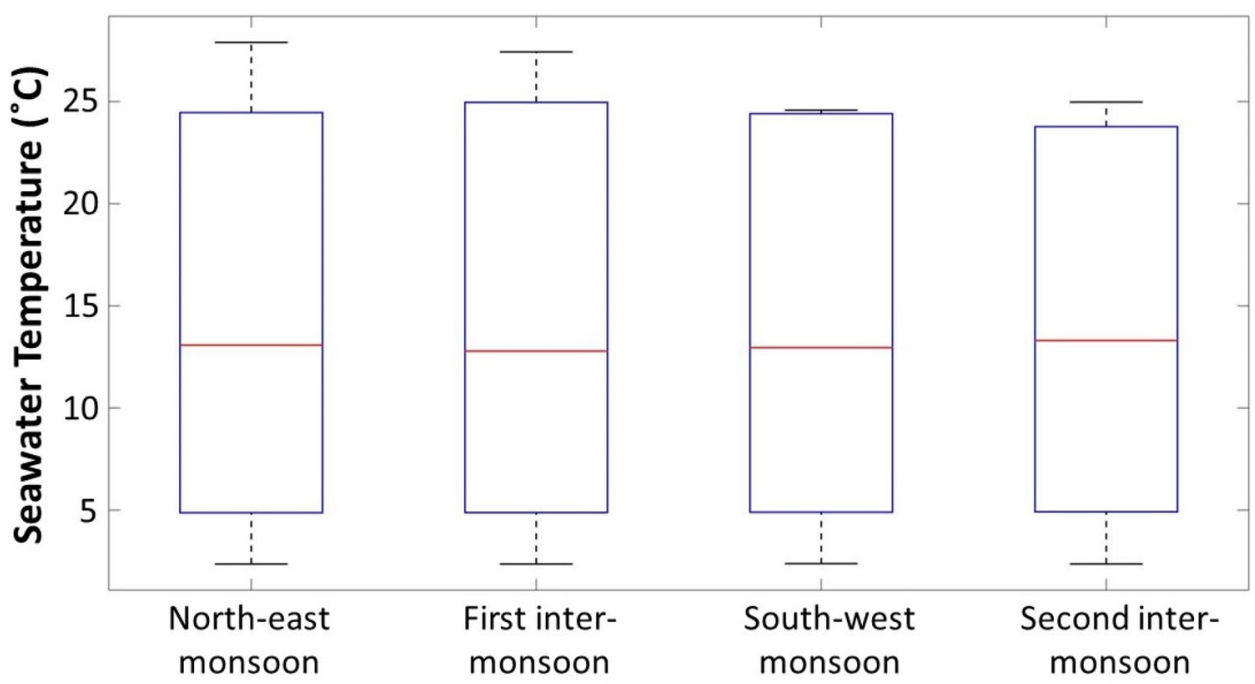

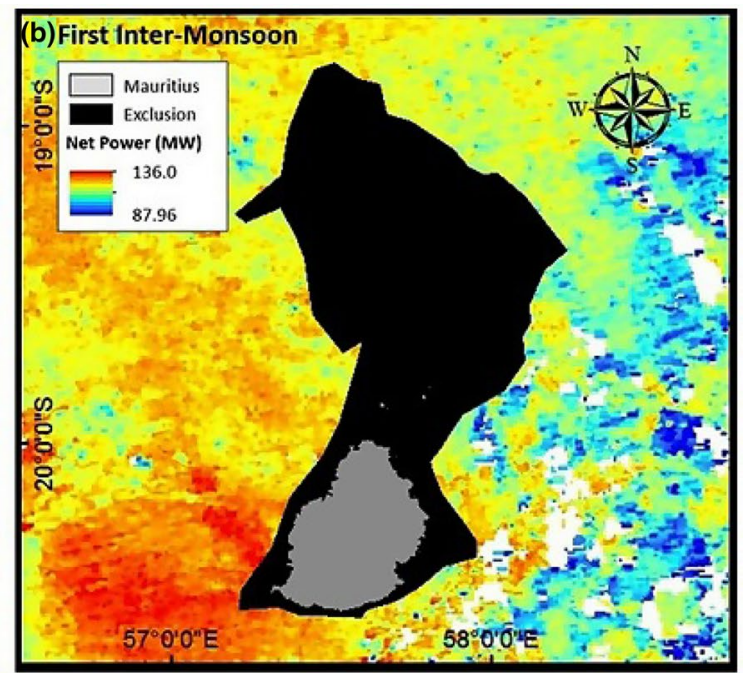
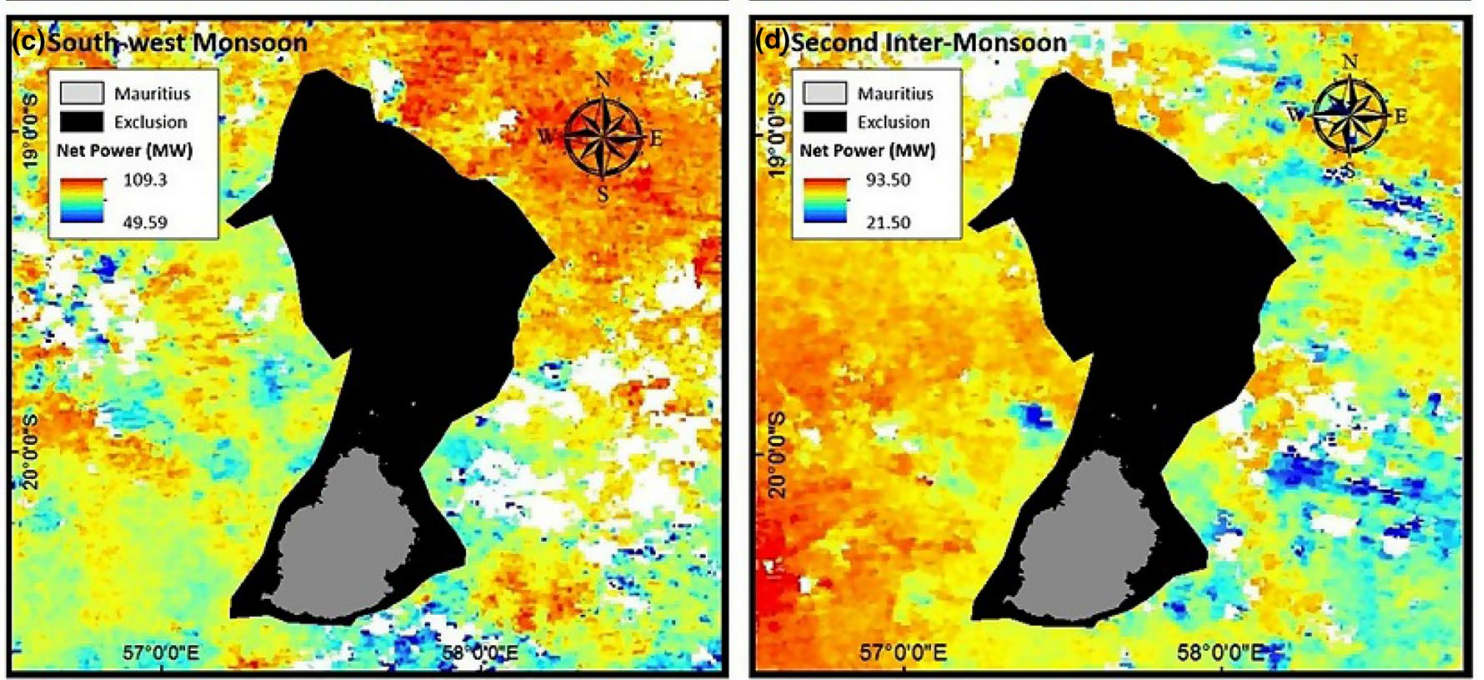

Fig. 8 Map delineating the ocean thermal energy conversion resources around Mauritius at a resolution of $1 \mathrm{~km}$ for the four monsoonal periods. The black region demonstrates the zone regarded as

inappropriate for the construction of the OTEC power plant due to water depths being lower than $1000 \mathrm{~m}$ 
are practically identical. The medians and upper quartiles of the distributions differ to some extent. The maxima on the other hand, reflecting the sea surface layer temperatures, vary significantly, with the north-east monsoon and first inter-monsoonal periods recording higher temperatures as compared to the south-west monsoon and second inter-monsoonal periods. This is indicative of the fact that the seawater temperatures differ significantly at ocean surface for the four monsoonal periods but as depth increases, the temperature difference decreases over the different time frames.

\section{OTEC resource potential}

A total of about 2 billion of data values have been assimilated by the model developed. The net power of ocean thermal energy conversion resources around Mauritius is depicted in Fig. 8. The spatial distribution of the resources is split into four temporal regimes corresponding to monsoonal periods and comprise of: the (a) north-east monsoon, (b) first inter-monsoon, (c) south-west monsoon, and (d) second inter-monsoon. According to a study performed, the most significant parameter dictating the most suitable site for OTEC installation is sea surface temperature [33].

As explained previously, the net power generated depends strongly on the available seawater temperature difference between surface and bottom layers. However, the temperature difference is dictated primarily by the warm surface temperature since water temperature near $1000 \mathrm{~m}$ depth varies little with longitude or season and varies only $1{ }^{\circ} \mathrm{C}$ or $2{ }^{\circ} \mathrm{C}$ with the latitude in the $\pm 20^{\circ}$ latitude band of interest [34]. Consequently, the spatial and temporal distributions of ocean thermal energy conversion resources around Mauritius can be explained on the basis of spatial and temporal variations in sea surface temperature.

The net power of OTEC resources around Mauritius is higher in the north-east monsoon (141.6-71.83 MW) followed by the first inter-monsoonal period (136.0 MW 87.96 MW) as compared to the net power of available resources in the south-west (109.3 MW 49.59 MW) and second inter-monsoonal (21.50 MW 93.50 MW) time frames. The results strongly correlates with the seasonal patterns of sea surface temperature around Mauritius where hotter sea surface temperatures are observed in the north-east monsoon and first inter-monsoon while colder temperatures are witnessed in the south-west monsoon and second inter-monsoon [35]. Additionally, the higher OTEC resource energy potential of the south-western zone of the island where deep cold waters are located at proximity from the shore is noticeable throughout the year.

The higher OTEC resource of the south-west region of Mauritius is attributed to the higher sea surface temperature of the region, which is inturn dictated by the south equatorial current (SEC) flowing westwards, driven by strong south-east trade winds and bringing the cold polar waters in its westward flowing motion. Due to the geographical position of Mauritius, the westward flow is split into two branches forming a zone of divergence from the south-west to the north-western waters of the island. Consequently, the hot waters of higher latitudes is trapped between the south-west and north-western regions of Mauritius. This encourages the placement of an OTEC power plant in the high-potential zone for the generation and subsequent injection of electricity in the distribution grid of the island. The next subsection discusses about identification of the optimum locations for the placement of the farm alongside with energy analysis.

\section{Optimum site selection}

OTEC power plants can either be built onshore or on offshore floating platforms. The onshore plant suffers from the drawbacks of long intake pipes for pumping seawater to land, high initial construction costs, large amounts of energy to operate the pumps and land-based environmental impacts [36]. Additionally, the land-based plant costs three times as much per unit power output as the sea-based plant due to the expense of the cold water pipe [37].

Consequently, we favour the sea-based floating platform system and emphasize our discussions on that marine-based technology in the current study. To ensure economic viability, OTEC needs to be installed in certain strategic locations. As a continuation of the analysis previously performed, the best locations for the construction of OTEC systems are identified as $Q$ and $R$ in Fig. 9c and benefit from a higher net power output throughout the year as compared to other regions of comparable distance to the coastline.

The main criteria influencing the selection of optimum locations is the difference in temperature between the surface and bottom layers. It can be observed from Fig. 9b that both sites selected lie in the $1750 \mathrm{~m}$ isobath, which gives an indication of deep cold water availability at a proximity of less than $5 \mathrm{~km}$ from the coastline (Fig. 9a). The distance of the optimum sites to the shore is another criteria influencing the selection since a smaller distance would imply less cabling, and therefore, less attenuation before the electricity is injected in the grid. As depicted in Fig. 9c, the $66 \mathrm{kV}$ transmission line lies in the region of Baie du Cap and Riambel which are located at short distances from optimum sites selected. The short distances from the point of harness to the injection end, would eventually imply reduced costs of underwater and land-based cabling infrastructure.

In addition to appropriate thermal gradient necessary for OTEC operation and proximity of sites of interest from the coastline, the baseline situation regarding sea state includes operational waves of up to $3.7 \mathrm{~m}$ in significant wave height and $7.5 \mathrm{~s}$ period. From the high-wave regime of the eastern 

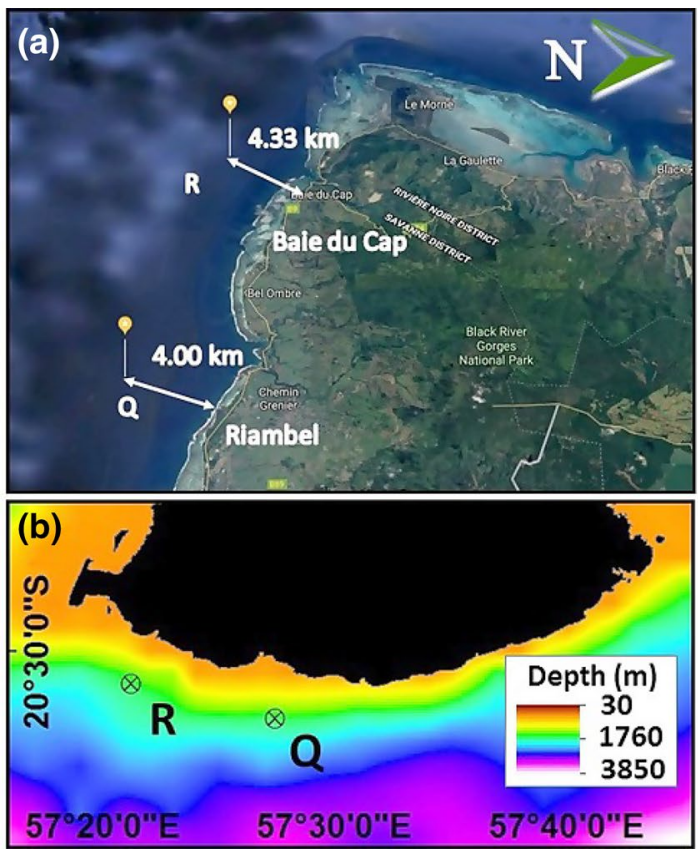

Fig. 9 a Distance of selected optimum sites $(R$ and $Q)$ from the shore of the southern region of Mauritius for the placement of OTEC power plant (as modified in Google Maps). b Map of the southern region of the island delineating the water depths of the sites of interest (Data

region to the relatively calmer sea state of the western side of the island, the significant wave height and energy period recorded are less than $3.7 \mathrm{~m}$ and $7.5 \mathrm{~s}$, respectively [2]. The significant wave height in the vicinity of the island of Mauritius never exceeded the operational baseline previously defined, which demonstrates the relatively propitious conditions prevailing.

Survival conditions are an important factor that need to be taken into account since Mauritius can encounter tropical (c)

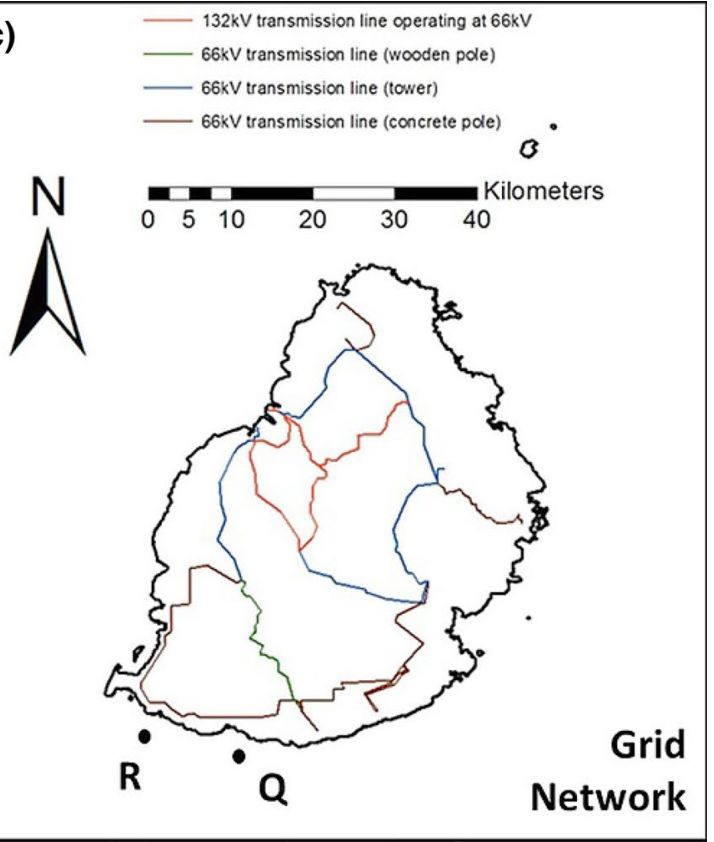

source: ETOPO1). c Map of Mauritius showing the distribution of high voltage transmission lines (Data source: Central Electricity Board)

cyclones occasionally, which lead to rough sea state that can potentially damage the OTEC structure. As from 2002, there was an average of 54 days when tropical systems were active in the south-west Indian Ocean basin, of which 20 had tropical cyclones active, or a system with winds of over $120 \mathrm{~km} / \mathrm{h}$ [38]. Tropical cyclones are very often accompanied by stormy, often destructive weather. Consequently, as a matter of safety and practicality, it is expected that platforms should be designed to survive 100-year storms [39].
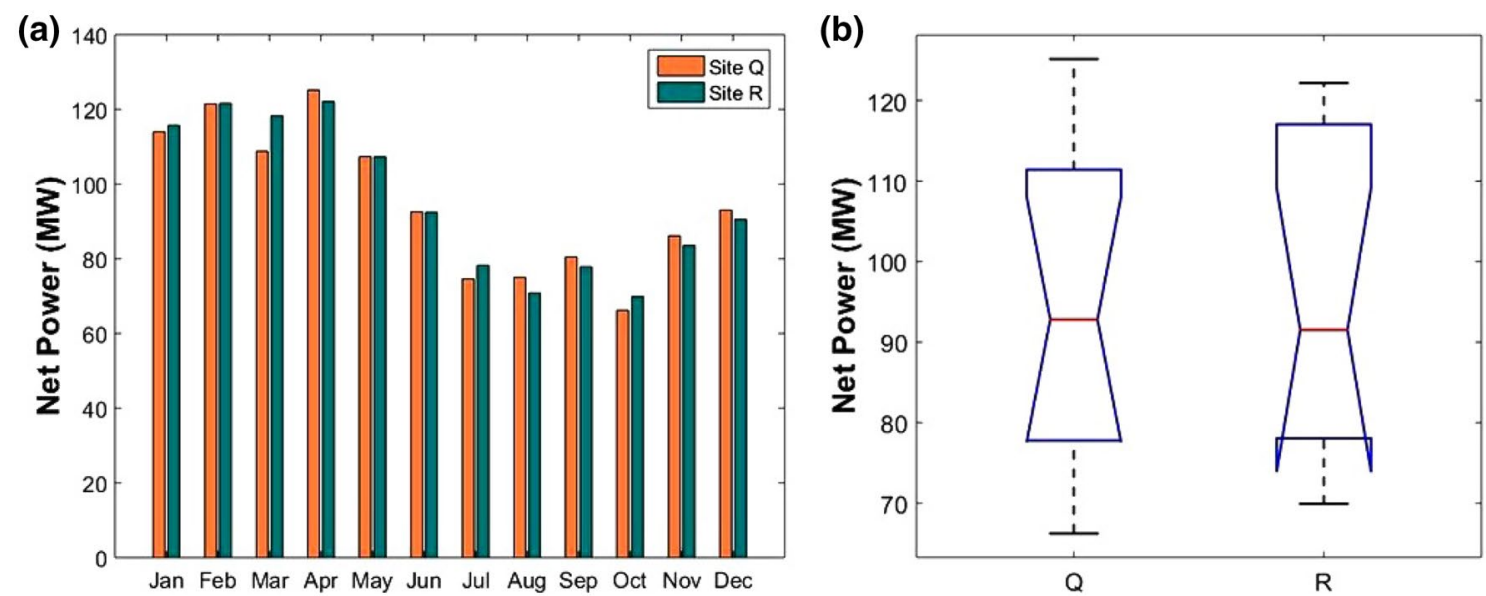

Fig. 10 a Barchart representing the variations in net power from OTEC resources at optimum sites $Q$ and $R$. b Boxplot illustrating the statistical differences between the datasets of the monthly mean daily net power generated over an annual time scale at the optimum sites 
Due to the low motility of OTEC platforms, several days are required to vacate an area. It is, therefore, imperative to design platform survival limits, with contingency plans around the worst possible situations. With the prowess of numerical forecasting techniques to predict the occurrence of storms several days ahead, technological advancements can innovate a retractable cold water pipe system to enable the platform to be moored to a safe region near the shore before the storm hits the region where the OTEC plant was initially deployed.

The variations in net power output from the optimum sites are represented in Fig. 10a. The higher power generated from the months of January-April is observable from the plot, whereby about $120 \mathrm{MW}$ can be harnessed from optimum sites. This represents about $25.6 \%$ of the peak power demand for Mauritius in 2016, which amounted to $468 \mathrm{MW}$ [40]. As compared to solar and wind energy technologies that are present in the national grid, OTEC is a much more continuous and constant form of energy, adaptable to the climate of Mauritius, owing to the little seasonal variations of upper and deep seawater temperatures of tropical latitudes.

Should maintenance operations be envisaged on OTEC power plants located at $Q$ and $R$, they need to be planned for the months of July-October where the net power output is at its lower operational mode. The annual mean daily net power potential of OTEC resources for optimum sites $Q$ and $R$ are 95.42 and $95.72 \mathrm{MW}$, respectively. Consequently, the power generation capacity of the OTEC system over an annual timescale represents about $20 \%$ of the peak power demand of the population of Mauritius.

Despite the comparable power generation of both sites, the interquartile range (IQR) of optimum site $Q$ is found to be smaller than that of site $R$. On the basis that the IQR is a better measurement of spread than the range and is not affected by the presence of outliers, it can be concluded that optimum site $Q$ is the better option for the placement of an OTEC plant. The smaller variations of the middle $50 \%$ of net power output throughout the year at site $Q$ gives an indication of the appropriateness for the integration in the electricity transmission grid of the island.

There is a need for a holistic and integrated framework to balance the increasing demand for marine space, coupled with environmental issues such as climate change. The somehow logical and vital step to meet these needs is shift towards a more strategic approach to marine governance via a marine spatial planning (MSP) process. A MSP is there to achieve sustainable use of the ocean whilst reducing conflicts between users and uses. The importance of a MSP in the development of an OTEC and the consideration of ocean-renewable industries in an MSP process is not well documented in the literature, though it has been found that a MSP is essential for developing such an industry [41].
The ocean space is home to various activities both distributed spatially and temporally, each managed more or less independently of each other. The proposed project should, therefore, consider the location of MPAs, marine reserves, traffic routes, whales' routes, underwater heritage sites, data buoys and other proposed economic developments such as mariculture farms. Consequently, the optimum sites have been selected far away from the above-mentioned group of spatial constraints for OTEC farm construction.

\section{Energy and exergy efficiency performances}

The energy efficiency of the proposed OTEC cycle at the optimum site $Q$ is given as follows:

$\eta_{\text {otec }}=\frac{P_{\text {net }}}{\dot{Q}_{\text {evp }}}=\frac{P_{\text {net }}}{\mathrm{UA}_{\text {evp }} \Delta T}=\frac{95.42 \mathrm{MW}}{\left(1410 \mathrm{MW} /{ }^{\circ} \mathrm{C}\right) \times\left(3.56^{\circ} \mathrm{C}\right)}=0.019$

As determined previously, $P_{\text {net }}$ for optimum site $Q$ is estimated to have a daily mean net power potential of 95.42 MW. Consequently, the energy efficiency of the OTEC cycle is evaluated at $1.9 \%$.

The exergy efficiency of the OTEC cycle proposed to be constructed at optimum site $Q$ is given by:

$\Psi=\frac{\eta_{\text {otec }}}{\eta_{\text {carnot }}}=\frac{\eta_{\text {otec }}}{1-\frac{T_{\mathrm{cw}}}{T_{\mathrm{ww}}}}=\frac{0.019}{1-\frac{2+273.15}{27+273.15}}=0.228$

As previously found, the cold seawater temperature over the year is estimated at $2{ }^{\circ} \mathrm{C}$ while the warm seawater temperature estimate amounts to $27^{\circ} \mathrm{C}$ over the same time scale. Consequently, the exergy efficiency of the OTEC cycle is evaluated at $22.8 \%$.

\section{Practical considerations}

The limitations of the OTEC system lie principally in the practical and engineering aspects related to the construction of the power plant. The main limitations are in the form of: Platform design, construction of cold water pipe, linkage to the shore, turbine considerations and choice of the working fluid. A brief description of each limitation mentioned is provided below:

\section{Platform design}

OTEC facilities need to be supported on floating platforms where water depths attain a minimum of $1000 \mathrm{~m}$. The most economical and durable structural material for the basic construction of floating OTEC platforms in the marine environment is a special mix of concrete reinforced with both conventional reinforcing steel and grouted pre-stressing steel 
tendons, moulded into the shape of an integrated contiguous honeycomb pattern, to provide maximum spatial tolerance [42]. However, the weight of such a structure would make it unwieldy. Consequently, difficulty arises when it comes to connecting the platform to the cold water pipe owing to the stresses caused from surface waves and currents [43]. The solution to this problem is to make the platform neutrally buoyant and moor it underwater, hence avoiding major stresses at the surface.

\section{Construction of cold water pipe (CWP)}

The CWP is subject to multiple forces in addition to the stresses at the connection point, and includes: drag by currents, oscillating forces due to vortex shredding, forces due to harmonic motion of the platform, forces due to drift of the platform and dead weight of the pipe [43]. Dynamic loadings on the pipe arising from the movement of waves, and stresses due to platform motions are regarded as problems influencing pipe design. Conventional CWP used are mainly available as a single piece pipe or segmented pipes. While transportation, deployment and decoupling of single piece pipe is difficult and requires towing from shore, segmented pipes on the other hand risk failure at the joints despite the ease of deployment. Material for the construction of CWP has evolved from corrugated steel pipe sections, flanged and bolted together to a fibre-reinforced-plastic design that is fixed to the seafloor by weights [44].

\section{Link to the shore}

The electrical energy generated from OTEC system may be transmitted to shore through electric cables that rest on ocean floor, or could be used on board to produce a chemical store of energy such as molecular hydrogen. The transmission of power to shore via bottom cables is considered as a reasonable extension of present technology. Despite the cost of cables, a cable of about $50 \mathrm{~km}$ long is quite practical, with power loss of about $0.05 \%$ per kilometre for alternating current and $0.01 \%$ per kilometre for direct current [43]. OTEC power plants in the range 100-400 MW are expected to be up to be about $320 \mathrm{~km}$ offshore, requiring DC transmission [45]. Consequently, the $5 \mathrm{~km}$ underwater cable required for the proposed power plant would result in practically insignificant power losses.

\section{Heat exchanger and turbine}

Heat exchangers are required in the design of the OTEC plant to allow for the transfer of heat from one fluid to another while keeping them separate. A common design is the shell-and-tube where water flows one way through the tubes while the working fluid flows through the shell. Among the factors for selection of materials for the fabrication of heat exchanges lie the durability, thermal conductivity, cost and resistance to seawater corrosion among others. The superior choice of material tends to side with titanium which exhibits better seawater performance, has good fabricability, and has an excellent service history in marine environments [46]. The turbine on the other hand needs to be large enough to accommodate the huge volumetric flow rates of working fluid vapour to maintain constant and practical amount of power output. Parametric studies revealed that a four-stage axial turbine could improve the efficiency up to $89 \%$, with attainable operational efficiencies of $53 \%$ derived from the $50 \mathrm{~kW}$ gross power installed capacity OTEC plant off the shore of Hawaii [47].

\section{Working fluid}

Generation of electricity efficiently from OTEC system requires a working fluid with a lower boiling point and a higher vapour pressure than water. There exists a list of working fluids including ammonia, propane and freon which are regarded as appropriate. Ammonia is generally used owing to its superior transport properties and availability at low cost [48]. The thermophysical property that gives

Table 4 Capital cost in million US dollars (M, USD) of a 100 MW closed cycle OTEC plant

\begin{tabular}{lll}
\hline Components & Description & Cost (USD) \\
\hline Equipment & Floating vessel hull ; Deck platform; Hull equipment; Pipes; Quarters & $85 \mathrm{M}$ \\
& Deck equipment: Turbine; Deck pumps & $100 \mathrm{M}$ \\
& Independent vertical pipe floater; Sub-sea condenser; Evaporator; Pumps & $95 \mathrm{M}$ \\
Electrical Infrastructure & Sub-sea cabling and land power substation system & $50 \mathrm{M}$ \\
Mooring and setup & Transport and installation & $30 \mathrm{M}$ \\
Operationalization & Commissioning, testing and start-up & $20 \mathrm{M}$ \\
Incidental expenses & Contingency & $20 \mathrm{M}$ \\
Planning and development & Marine spatial planning & $10 \mathrm{M}$ \\
Total & & $410 \mathrm{M}$ \\
\hline
\end{tabular}


ammonia its general superiority is its relatively high thermal conductivity [49]. Nonetheless, care should be taken when handling these working fluids since many of the above-mentioned ones are considered as environmentally unacceptable. Leaks could pose a potential threat to the environment, with increasing greenhouse gases or ozone-depleting gases. Additionally, by applying a partial vacuum through the lowering of pressure, the boiling point of water can be reduced to the temperature of warm water intake [43]. This way, the warm seawater can be used instead as the working fluid, with the system providing additional power and substantial quantities of distilled water.

\section{Cost-benefit analysis}

A cost analysis can be measured in different ways, with each way of accounting for the cost of power generation bringing its own insights. The overall costs of implementing the OTEC project would comprise of equipment costs, total installation costs, fixed and variable operating and maintenance costs, net present value costs among others. However, we restrict our discussion to a simplified version to allow greater scrutiny of the underlying data and improve transparency on the main costs involved. Table 4 shows the estimated cost of a 100 MW OTEC power plant with its underwater cabling and supporting vessel facilities as initially proposed by Srinivasan et al. [50] and slightly modified to account for additional expenses pertaining to planning and development operations involved.

An annual expenditure of about $1.5 \%$ of the capital cost is expected as operational and maintenance cost (O\&M), Co [51]. Consequently, over 1 year time frame, about $\$ 6.15$ million is required as O\&M costs of the OTEC farm.

The annual mean daily production of electricity of optimum site $Q$ amounts to $95.42 \mathrm{MW}$. The capacity factor of OTEC systems have been evaluated at $80 \%$, even from a modest estimate of it [52]. In addition, the net power that can be derived from OTEC technologies approximates to about $65 \%$ of the gross power generated [53]. Therefore, the net amount of power generation from the power plant situated at site $Q$ would be, on average: $95.42 \times 24 \times 365 \times 0.8 \times 0.65 \mathrm{MWh}=434,657 \mathrm{MWh}=$ $434.7 \mathrm{GWh}=434,700,000 \mathrm{kWh}$

In estimations where profits are generated after a certain time lapse after investments, the net present value (NPV) estimations are considered. Banerjee et al. [54] proposed the following relationship to determine the cost of electricity from the NPV concept pertaining to the generation cost alone and excluding the insurance cost, local taxes, profit margin among others.

Cost of electricity production (per $\mathrm{kWh}$ )

$$
=\frac{\left\{\mathrm{Cc}+\sum_{0}^{t}[0.01 x \cdot \mathrm{Cc} /(1+r) t]\right\}}{\left\{\sum_{0}^{t}[E /(1+r) t]\right\}}
$$

where $\mathrm{Cc}$ is the capital cost, $E$ is the annual energy production, $t$ is the life period, $r$ represents the discount rate considered, while the operational cost is $x$ percent of the capital cost Cc.

Using Eq. (24) and considering 8\% discount rate for the OTEC system having 30 years life time, would give a discount factor, $D F$, equivalent to: $\mathrm{DF}=((1+0.08) 30-1) /[0.08 \times(1+0.08) 30]=12.11$.

The present value cost (PVC) is given by: $\mathrm{PVC}=\mathrm{Cc}+\mathrm{Co} \times \mathrm{DF}$, which gives a value of $\$ 484.5$ million. In addition, the present value of energy (PVE) is given by: $\mathrm{PVE}=434,700,000 \times 12.11=5,264,217,000 \mathrm{kWh}$. Consequently, the cost per $\mathrm{kWh}$ is given by the ratio of $\mathrm{PVC}$ and PVE and is numerically equal to $9.2 \mathrm{c} / \mathrm{kWh}$.

The central electricity board (CEB) of Mauritius is primarily responsible for the electricity supply, transmission, and distribution around the island. The price of electricity purchase by the CEB for the year 2018 is at a standard rate of $23.1 \mathrm{c} / \mathrm{kWh}$ [55]. Consequently, the profit per $\mathrm{kWh}$ of electricity generated by the OTEC system turns out to be around $13.9 \mathrm{c} / \mathrm{kWh}$. The yearly revenue generated by the OTEC farm is, therefore, estimated to be $\$ 60.4$ million. During the 30 years lifetime, the revenue prediction is estimated to have a $10 \%$ increase in electricity purchase cost as provided in Table 5.

It can be observed from Table 5 that within the first 7 years, the initial investment is recovered. During the whole 30 years of lifetime of the OTEC system, profits of the order of 4.5 times the initial investment will be generated. This shows how profitable it is to have an OTEC power plant at the proposed location.
Table 5 Estimated yearly revenue excluding yearly maintenance costs in million US dollars (M, USD) of a $100 \mathrm{MW}$ closed cycle OTEC plant

\begin{tabular}{lllllll}
\hline Year & $1-5$ & $6-10$ & $11-15$ & $16-20$ & $21-25$ & $26-30$ \\
\hline Revenue per year & $60.4 \mathrm{M}$ & $66.4 \mathrm{M}$ & $73.1 \mathrm{M}$ & $80.4 \mathrm{M}$ & $88.4 \mathrm{M}$ & $97.3 \mathrm{M}$ \\
Total revenue (per 5 year) & $302.1 \mathrm{M}$ & $332.0 \mathrm{M}$ & $365.5 \mathrm{M}$ & $402.0 \mathrm{M}$ & $442.0 \mathrm{M}$ & $486.5 \mathrm{M}$ \\
Net revenue over the 30 years lifetime & & & & & & $2330.1 \mathrm{M}$ \\
\hline
\end{tabular}




\section{Benefits from an OTEC industry}

Complementary with the OTEC, there are numerous social, environmental and economic benefits to deep sea water. Due to its innate characteristics, that is, low temperature, high purity, nutrient and mineral (organic and inorganic) content and concentration, this water constitutes numerous environmental benefits. For instance, the high concentration of organic nutrients present in the pumped water, when released back to the sea, would definitely attract plankton (larval fish and other suspended organisms) and eventually larger fish as we move up the food chain. This may potentially contribute to addressing the global problem of food security.

Air conditioning and desalination are other potential derivatives of an OTEC system. In air conditioning, the near zero temperature deep sea water pumped by OTEC systems provides air condition for buildings. This would indeed save on the monthly electricity bill of several prosumers of a targeted region. Combined with a desalination plant in a hybrid system which uses both open-cycle- and closed-cycle systems, the OTEC has a great potential to resolve the potable water problem. As compared to surface water distillation plants, the deep ocean water desalination plant is more flexible in terms of energy usage. In places where potable water is an issue, the hybrid farm would offer a more economic investment solution.

OTEC also allows for the cultivation of temperate crops in tropical regions. The agricultural land is chilled by the cold deep sea water which replicates the temperature difference of cool soil and warm air of the temperate regions, thereby allowing for the different produces to grow. Moreover, the aquaculture industry is the main indirect beneficiary of an OTEC system across the globe. The artificial upwelling of nutrients contributes largely to the recovery and amplification of fisheries resources. In addition, the phytoplankton, besides being an additional source of food for fish, comprise numerous other economic benefits such as acting as bio-fertilisers, natural wastewater treatment, cosmetic and nutrition.

\section{Environmental impact assessment}

Marine organisms such as plankton consume $\mathrm{CO}_{2}$ during photosynthesis and in the formation of shells. $\mathrm{CO}_{2}$ sequestration occurs whenever the dead cells of these organisms or other marine species feeding on them sink to the ocean floor with enriched carbonate content, thereby maintaining $\mathrm{CO}_{2}$ balance in the global environment. The artificial upwelling of deep cold water destabilizes the $\mathrm{CO}_{2}$ balance established. Although the increase in plankton concentration at the surface would help lower greenhouse gas level in the atmosphere by consuming more $\mathrm{CO}_{2}$ over the ocean surface, a high amount of dissolved $\mathrm{CO}_{2}(g)$ is likely to be released from temperature rise and the pressure release of the upwelled cold water [52]. Green and Guenther [56], however, stated that if the cold upwelled water, instead of being discharged into the ocean is used for mariculture, there exists the possibility that the cultured marine plants would absorb the extra $\mathrm{CO}_{2}(g)$, and therefore, neutralize the impact on the environment [56].

For many SIDS, the degradation of coral reef ecosystems can have severe effects on their economic structure, arising principally from their reliance on the fishing and tourism industry. The physiology of coral reef ecosystems, in which symbiotic relationships exist among the marine organisms, is often disturbed by radical changes in sea temperature. A change in seawater temperatures of a few degrees can upset the coral's ability to convert sunlight into biomass, thereby upsetting the food supply on which fish are heavily reliant. The artificial upwelling of deep cold water from an OTEC system need to be coupled to adequate monitoring techniques of seawater temperatures not to impact negatively on coral reef ecosystems. Several studies in the literature have proposed OTEC technology as having the potential to counter the problem of coral bleaching through the maintenance of seawater temperatures at an appropriate level [52]. The hypothetical location of about 1000 plants of $200 \mathrm{MW}$ each in the Gulf of Mexico has been simulated to reduce sea surface temperature by $0.3^{\circ} \mathrm{C}$, which is regarded as physically insignificant even at such an unlikely scale [43].

\section{IEC compliance}

An intergovernmental collaboration between countries resulted in the setting up of the Ocean Energy Systems Technology Collaboration Programme (OES), which operates under the framework established by the International Energy Agency. Standards and protocols for the management of marine energy conversion systems, with emphasis on the conversion of wave, tidal and OTEC technologies into electricity are managed by the IEC TC-114 which is a technical committee (TC) of the International Electro-technical Commission. The partnership between the OES and IEC aims at developing a unified international standard in view of providing the guidelines for suitable site selection, design bases and productivity estimations for OTEC plants based on objective standards [57]. The standardization is an important facet to be considered when implementing the project in the waters of Mauritius to avoid the negative impact of OTEC technologies on coastal wildlife, such as mangroves and corals.

\section{Conclusions}

A model has been designed to investigate on the ocean thermal energy conversion resources around Mauritius. The model implementation is based on the underlying principle 
of thermal stratification of seawater, whereby the warm water of the upper thermocline is inherently less dense and has the tendency to rise above the colder, denser water of deeper layers. About 2 billion of data values have been assimilated by the developed model and integrated in a proposed OTEC power generation model, which resulted in the production of net power generation maps describing the spatial distribution of OTEC resources over the four monsoonal periods of the year.

From the maps, the appropriateness of the south-western region of the island is revealed. We attribute the better conditions of this region for OTEC system implementation to the higher sea surface temperatures and deep cold water availability at a proximity of less than $5 \mathrm{~km}$ from the coastline. We further investigate on the power generation capacity of two optimum sites in the southern part of the island. The annual mean daily power generation capacity is found to be about 95 MW, representing about $20 \%$ of the peak power demand of the island. Additionally, energy and exergy efficiencies of the OTEC cycle are investigated and found to be 1.9 and $22.8 \%$, respectively.

A cost-benefit analysis performed suggests that cost estimates for setting up the farm is around $\$ 410$ million, with annual operational and maintenance cost of about $\$ 6.15$ million. Further analysis reveals that the initial cost of investment can be recovered within the first 7 years of the plant operation, while during the 30 years plant lifetime, profits of the order of about $\$ 1920$ million can be generated. The project is, therefore, found to be profitable in the long run.

The practical applicability of the model-implemented target countries having large exclusive economic zones and vast expanse of the ocean, to determine the best place for constructing an OTEC power plant. Consequently, the results are believed to reduce time and money for locating optimum OTEC sites. In addition, the developed thermocline model could provide a practical way of estimating seawater temperature at certain depths, without the need of deploying costly measuring instruments.

Acknowledgements We would like to acknowledge the Mauritius Oceanography Institute for the provision of adequate facilities and data to carry out research presented in this paper. We are grateful to the director of the institute, Dr. Ruby Moothien Pillay, for her support and interest in the promotion of marine renewable energy in Mauritius. We gratefully acknowledge the contributions of Ms Preeti Oogarah, Mrs Harree Somah Luxmibye and Ms Geetika Kalleechurn for their suggestions with regard to the chemical/biological aspects of the research. We thank our IT officer, Mr Prathav Askoolum for his support pertaining to the computational aspects of the research conducted. Thanks are extended to Mrs Asha Moonesawmy, our librarian, for providing us with the relevant books and manuscripts for the research performed. We would like to thank the two anonymous reviewers for their helpful and constructive comments. Special thanks to the National Oceanic and Atmospheric Administration (NOAA), and the Asia-Pacific DataResearch Center for their respective contributions. We appreciate the inputs of the Cartography section of the Ministry of Housing and Lands together with those of the Central Electricity Board.

\section{Compliance with ethical standards}

Conflict of interest On behalf of all authors, the corresponding author states that there is no conflict of interest.

Data availability The data that support the findings of this study are available from the Mauritius Oceanography Institute but restrictions apply to the availability of these data, which were used under approval for the current study, and so are not publicly available. Data are, however, available from the author upon reasonable request and with permission of the Mauritius Oceanography Institute.

Open Access This article is distributed under the terms of the Creative Commons Attribution 4.0 International License (http://creativeco mmons.org/licenses/by/4.0/), which permits unrestricted use, distribution, and reproduction in any medium, provided you give appropriate credit to the original author(s) and the source, provide a link to the Creative Commons license, and indicate if changes were made.

\section{References}

1. Ossenbrink R.: Skytron energy connects solar power plant to the grid in Mauritius. http://www.sunwindenergy.com/photovoltaics/ skytron-energy-connects-solar-power-plant-grid-mauritius (2014). Accessed 6 Nov 2017

2. Doorga, J.R.S., Chinta, D., Gooroochurn, O., Rawat, A., Ramchandur, V., Motah, B.A., Sunassee, S., Samyan, C.: Assessment of the wave potential at selected hydrology and coastal environments around a tropical island, case study: Mauritius. Int. J. Energy Environ. Eng. 9(2), 135-153 (2018)

3. SM: Population and Vital Statistics - Year 2016. http://statsmauri tius.govmu.org/English/Publications/Pages/Pop_and_Vital_Stats _Yr16.aspx (2017). Accessed 6 Nov 2017

4. Caribbean development bank: Climate resilience strategy 20122017. http://www.caribank.org/wp-content/uploads/2016/03/ BD23_12Rev1TA-Paper_Climate-ResilienceStrategy_FINAL .pdf (2012). Accessed 7 Nov 2017

5. REN21: Renewable energy policy network for the 21st century. http://www.ren21.net/Portals/0/documents/Resources/GSR/2014/ GSR2014_full\%20report_low\%20res.pdf (2014). Accessed 7 Nov 2017

6. Mauritius Board of Investment: Budget highlights 2016/2017. http://www.investmauritius.com/budget2016/Green.html (2016). Accessed 7 Nov 2017

7. Fujita, R., Markham, A.C., Diaz, J.E.D., Garcia, J.R.M., Scarborough, C., Greenfield, P., Aguilera, S.E.: Revisiting ocean thermal energy conversion. Mar. Policy 36(2), 463-465 (2012)

8. Dugger, G.L., Francis, E.J., Avery, W.H.: Technical and economic feasibility of ocean thermal energy conversion. Sol. Energy 20(3), 259-274 (1978). (36(2))

9. VanZwieten, J.H., Rauchenstein, L.T., Lee, L.: An assessment of Florida's ocean thermal energy conversion (OTEC) resource. Renew. Sustain. Energy Rev. 75, 683-691 (2017)

10. Binger, A.: Potential and future prospects for ocean thermal energy conversion (OTEC) in small islands developing states (SIDS). Small Island Developing States, on internet. http://www. sidsnet.org/docshare/energy/20040428105917_OTEC_UN.pdf (2006). Accessed 9 Nov 2017 
11. Makai Ocean Engineering: Kailua (HI), USA: Makai connects world's largest ocean thermal plant to U.S. grid. http://www.makai .com/makai-news/2015_08_29_makai_connects_otec/ (2015). Accessed 9 Nov 2017

12. Koto, J., Negara, R.B.: $10 \mathrm{MW}$ plant ocean thermal energy conversion in Morotai Island, North Maluku, Indonesia. Sci. Eng. 8, 7-14 (2016)

13. tidalenergytoday: Global map of OTEC plants comes to light. https://tidalenergytoday.com/2017/06/19/global-map-of-otecplants-comes-to-light/ (2017). Accessed 10 Nov 2017

14. Payet, R.: Research, assessment and management on the Mascarene Plateau: a large marine ecosystem perspective. Philos. Trans. R. Soc. Lond. A Math. Phys. Eng. Sci. 363(1826), 295-307 (2005)

15. Montaggioni, L.: Coral reefs and quaternary shorelines in the Mascarene archipelago, Indian Ocean. In Proc. 2nd Int. Coral Reef Symp, vol. 1, pp. 579-593 (1974)

16. Ramage, C.S.: Indian ocean surface meteorology and oceanography. Mar. Biol. 7, 11-30 (1969)

17. Colling, A.: Ocean Circulation, p. 286. Butterworth-Heinemann, Milton Keynes (2002)

18. Sandwell, D.T., Smith, W.H.: Global marine gravity from retracked Geosat and ERS1 altimetry: Ridge segmentation versus spreading rate. J. Geophys. Res. Solid Earth 114(B1), 1-18 (2009)

19. Nihous, G.C.: Mapping available ocean thermal energy conversion resources around the main Hawaiian Islands with state-of-the-art tools. J. Renew. Sustain. Energy 2(4), 043104 (2010)

20. Syamsuddin, M.L., Attamimi, A., Nugraha, A.P., Gibran, S., Afifah, A.Q., Oriana, N.: OTEC potential in the Indonesian seas. Energy Proc. 65, 215-222 (2015)

21. Argo: Argo float data and metadata from Global Data Assembly Centre (Argo GDAC). SEANOE. https://doi.org/10.17882/42182 (2000)

22. Nagurny, J., Martel, L., Heimiller, D., Gray-Hann, P., Hanson, H., Jansen, E., Plumb, A., Rauchenstein, L.: Modeling of ocean thermal energy extraction visualization. In: Proceedings of the IEEE Oceans Conference, no. 110422-055 Kona, Hawaii (2011)

23. Rauchenstein, L.T.: Global distribution of ocean thermal energy conversion (OTEC) resources and applicability in U.S. Waters near Florida [thesis]. Boca Raton (FL): Florida Atlantic University (2012)

24. Nihous, G.C.: A preliminary assessment of ocean thermal energy conversion resources. J. Energy Res. Technol. 129(1), 10-17 (2007)

25. Ascari, M.B., Hanson, H.P., Rauchenstein, L., Van Zwieten, J., Bharathan, D., Heimiller, D., Langle, N., Scott, G.N., Potemra, J., Nagurny, N.J., Jansen, E.,: Ocean Thermal Extractable Energy Visualization-Final Technical Report on Award DE-EE0002664. October 28, 2012 (No. DOE/EE0002664-1). Lockheed Martin Mission Systems and Sensors (2012)

26. Ahmadi, P., Dincer, I., Rosen, M.A.: Energy and exergy analyses of hydrogen production via solar-boosted ocean thermal energy conversion and PEM electrolysis. Int. J. Hydrog. Energy 38(4), 1795-1805 (2013)

27. Sinama, F., Martins, M., Journoud, A., Marc, O., Lucas, F.: Thermodynamic analysis and optimization of a 10 MW OTEC Rankine cycle in Reunion Island with the equivalent Gibbs system method and generic optimization program GenOpt. Appl. Ocean Res. 53, 54-66 (2015)

28. Miller, A., Rosario, T., Ascari, M.: Selection and validation of a minimum-cost cold water pipe material, configuration, and fabrication method for ocean thermal energy conversion (OTEC) systems. In: Proceedings of SAMPE (2012)

29. Talley, L.D.: Descriptive Physical Oceanography: An Introduction. Academic Press, New York (2011)

30. MathWorks, Inc.: Curve fitting toolbox: for use with MATLAB: user's guide. MathWorks (2002)
31. Badal, M.R., Rughooputh, S.D.D.V., Rydberg, L., Robinson, I.S., Pattiaratchi, C.: Eddy formation around South West Mascarene Plateau (Indian Ocean) as evidenced by satellite 'global ocean colour' data. West. Indian Ocean J. Mar. Sci. 8(2), 139-145 (2009)

32. Yoon, J.I., Seol, S.H., Son, C.H., Jung, S.H., Kim, Y.B., Lee, H.S., Kim, H.J., Moon, J.H.: Analysis of the high-efficiency EP-OTEC cycle using R152a. Renew. Energy 105, 366-373 (2017)

33. Khare, A., Majumder, M.: Development of location suitability index for ocean thermal energy conversion systems. Int. J. Control Theory Appl. 10(6), 63-71 (2017)

34. Dugger, G.L., Henderson, R.W., Francis, E.J., Avery, W.H.: Projected costs for electricity and products from OTEC facilities and plantships. J. Energy 5(4), 231-236 (1981)

35. Ramchandur, V., Rughooputh, S.D., Bhoojawon, R., Motah, B.A.: Assessment of chlorophyll-a and sea surface temperature variability around the Mascarene Plateau, Nazareth Bank (Mauritius) using satellite data. Indian J. Fish. 64(4), 1-8 (2017)

36. Devis-Morales, A., Montoya-Sanchez, R.A., Osorio, A.F., OteroDiaz, L.J.: Ocean thermal energy resources in Colombia. Renew. Energy 66, 759-769 (2014)

37. Bechtel, M., Netz, E.: OTEC-Ocean Thermal Energy Conversion (2016)

38. RSMC La Reunion: Cyclone Season 2001-2002. Meteo-France. (2013)

39. Sands, M.D.: Ocean thermal energy conversion (OTEC) programmatic environmental analysis (No. LBL-10511-v1). Ernest Orlando Lawrence Berkeley National Laboratory, Berkeley, CA (US)(1980)

40. SM: Energy and Water Statistics - Year 2016. http://statsmauri tius.govmu.org/English/Publications/Documents/EI1317/Energ y_Water_Stats_Yr2016.pdf (2017). Accessed 16 Feb 2018

41. Ehler, C.: Marine Spatial Planning: An Idea Whose Time Has Come. Annual Report on Implementing Agreement on Ocean Energy, Paris: International Energy Agency, pp 96-100 (2011)

42. Yee, A.A.: OTEC Platform. In: Large Floating Structures. Springer, Singapore, pp. 261-280 (2015)

43. Twidell, J., Weir, T.: Renewable Energy Resources. Routledge, London (2015)

44. Muralidharan, S.: Assessment of ocean thermal energy conversion (Doctoral dissertation, Massachusetts Institute of Technology) (2012)

45. Traut, R.T., Kurt, J.P., DiPietro, F.M., Roberts, K.P.: Electrical/ mechanical evaluation of high voltage dielectrics for OTEC riser cables. In: 1980 IEEE International Conference on Electrical Insulation, pp. 113-117. IEEE (1980)

46. Kapranos, P., Priestner, R.: Overview of metallic materials for heat exchangers for ocean thermal energy conversion systems. J. Mater. Sci 22(4), 1141-1149 (1987)

47. Ravindran, M., Abraham, R.: The Indian $1 \mathrm{MW}$ demonstration OTEC plant and the development activities. In OCEANS'02 MTS/IEEE, vol. 3, pp. 1622-1628. IEEE (2002)

48. Ayub, Z.: Status of enhanced heat transfer in systems with natural refrigerants. J. Therm. Sci. Eng. Appl. 2(4), 044001 (2010)

49. Ganic, E.N., Wu, J.: On the selection of working fluids for OTEC power plants. Energy Conver. Manage. 20(1), 9-22 (1980)

50. Srinivasan, N., Sridhar, M., Agrawal, M.: Study on the cost effective ocean thermal energy conversion power plant. In: Offshore Technology Conference. Offshore Technology Conference (2010)

51. Vega, L.A.: Economics of ocean thermal energy conversion (OTEC). In: Seymour, R.J. (ed.) Ocean Energy Recovery: The State of the Art. American Society of Civil Engineers, New York (1992)

52. Banerjee, S., Duckers, L., Blanchard, R.E.: A case study of a hypothetical $100 \mathrm{MW}$ OTEC plant analyzing the prospects of OTEC technology. In: Dessne, P., Golmen, L. (eds.) OTEC Matters, vol. 1, pp. 98-129 (2015) 
53. Vega, L.A.: Ocean Thermal Energy Conversion, OTEC, pp. 1-22 (1999)

54. Banerjee, S., Duckers, L.J., Blanchard, R.E., Choudhury, B.K.: Ocean energy systems: economy evaluation. In: Encyclopedia of Energy Engineering and Technology, pp. 1-8 (2015). ISBN: 9780849338960

55. World Bank Group: Doing business 2018 - Mauritius. http:// www.doingbusiness.org//media/wbg/doingbusiness/documents/ profiles/country/mus.pdf (2018). Accessed 7 Mar 2018
56. Green, H.J., Guenther, P.R.: Carbon dioxide release from OTEC cycles. In: Ocean Energy Recovery, pp. 348-357. ASCE (1989)

57. Ecomagazine.com: New Global Standards Could Boost OTEC. https://www.ecomagazine.com/news/regulation/new-global-stand ards-could-boost-otec (2017). Accessed 8 Mar 2018

Publisher's Note Springer Nature remains neutral with regard to jurisdictional claims in published maps and institutional affiliations. 